\title{
Dehydration in the tropical tropopause layer estimated from the water vapor match
}

\author{
Y. Inai ${ }^{1, *}$, F. Hasebe ${ }^{2}$, M. Fujiwara ${ }^{2}$, M. Shiotani ${ }^{3}$, N. Nishi ${ }^{4, * *}$, S.-Y. Ogino ${ }^{5}$, H. Vömel ${ }^{6}$, S. Iwasaki ${ }^{7}$, and T. Shibata ${ }^{8}$ \\ ${ }^{1}$ Graduate School of Science, Tohoku University, Sendai, Japan \\ ${ }^{2}$ Faculty of Environmental Earth Science, Hokkaido University, Sapporo, Japan \\ ${ }^{3}$ Research Institute for Sustainable Humanosphere, Kyoto University, Uji, Japan \\ ${ }^{4}$ Geophysical Institute, Kyoto University, Kyoto, Japan \\ ${ }^{5}$ Japan Agency for Marine-Earth Science and Technology, Yokosuka, Japan \\ ${ }^{6}$ GRUAN Lead Center, Deutscher Wetterdienst, Lindenberg, Germany \\ ${ }^{7}$ Department of Earth and Ocean Science, National Defense Academy, Yokosuka, Japan \\ ${ }^{8}$ Graduate School of Environmental Studies, Nagoya University, Nagoya, Japan \\ * now at: Research Institute for Sustainable Humanosphere, Kyoto University, Uji, Japan \\ ** now at: Faculty of Science, Fukuoka University, Fukuoka, Japan \\ Correspondence to: Y. Inai (yoichi_inai@rish.kyoto-u.ac.jp)
}

Received: 22 November 2012 - Published in Atmos. Chem. Phys. Discuss.: 8 January 2013

Revised: 17 July 2013 - Accepted: 18 July 2013 - Published: 2 September 2013

\begin{abstract}
We apply the match technique, whereby the same air mass is observed more than once and such cases are termed a "match", to study the dehydration process associated with horizontal advection in the tropical tropopause layer (TTL) over the western Pacific. The matches are obtained from profile data taken by the Soundings of Ozone and Water in the Equatorial Region (SOWER) campaign network observations using isentropic trajectories calculated from European Centre for Medium-Range Weather Forecasts (ECMWF) operational analyses. For the matches identified, extensive screening procedures are performed to verify the representativeness of the air parcel and the validity of the isentropic treatment, and to check for possible water injection by deep convection, consistency between the sonde data and analysis field referring to the ozone conservation. Among the matches that passed the screening tests, we identified some cases corresponding to the first quantitative value of dehydration associated with horizontal advection in the TTL. The statistical features of dehydration for the air parcels advected in the lower TTL are derived from the matches. The threshold of nucleation is estimated to be $146 \pm 19 \%(1 \sigma)$ in relative humidity with respect to ice $\left(\mathrm{RH}_{\text {ice }}\right)$, while dehydration seems to continue until $\mathrm{RH}_{\text {ice }}$ reaches about $75 \pm 23 \%$ $(1 \sigma)$ in the altitude region from 350 to $360 \mathrm{~K}$. The efficiency
\end{abstract}

of dehydration expressed by the relaxation time required for the supersaturated air parcel to approach saturation is empirically determined from the matches. A relaxation time of approximately one hour reproduces the second water vapor observation reasonably well, given the first observed water vapor amount and the history of the saturation mixing ratio during advection in the lower TTL.

\section{Introduction}

Water vapor has strong absorption/emission bands in the infrared region; accordingly, it has a strong greenhouse effect. In the troposphere and stratosphere, it plays an important role in the radiation balance of the earth (e.g., Forster and Shine, 1999; Solomon et al., 2010), and it influences atmospheric chemistry via its product, the hydroxyl radical $(\mathrm{OH})$ (Stenke and Grewe, 2005), and via polar stratospheric clouds (PSCs) (Saitoh et al., 2006).

The distribution of stratospheric water vapor is roughly understood as the sum of the production of water vapor caused by methane oxidation and transport into the stratosphere of dehydrated dry air through the tropical tropopause region (Kley et al., 2000). The former mechanism is well 
understood, whereas the dehydration process in the tropical tropopause region is somewhat unclear despite the fact that it is considered a key factor for understanding stratospheric water vapor, including its unexplained long-term change (Oltmans and Hofmann, 1995; Kley et al., 2000; Oltmans et al., 2000; Scherer et al., 2008; Fujiwara et al., 2010; Hurst et al., 2011).

In the late 1990s, many studies investigated the transition in meteorological features that occurs within a layer of several kilometers in height from the troposphere to the stratosphere in the tropics, and the findings of these studies resulted in the concept of the tropical tropopause layer (TTL; e.g., Highwood and Hoskins, 1998; Fueglistaler et al., 2009). In turn, this resulted in an innovative hypothesis, the "cold trap" dehydration hypothesis, regarding the nature of dehydration processes in the tropical tropopause region, i.e., air is dehydrated during horizontal advection through the cold trap region in the western tropical Pacific (Holton and Gettelman, 2001). This cold trap dehydration hypothesis, by considering quasi-isentropic motion, indicates that the local temperature minimum can effectively dehydrate the air mass entering the stratosphere. This hypothesis was supported by General Circulation Model (GCM) simulations (Hatsushika and Yamazaki, 2003). As a result, this dehydration process is considered to be efficiently driven by equatorially symmetric atmospheric gyres and by the "cold trap" that forms in the TTL as a response to heating at the lower boundary in the western tropical Pacific (Matsuno-Gill pattern; Matsuno, 1966; Gill, 1980).

Fueglistaler et al. (2005) and Ploeger et al. (2011) estimated the water vapor amount on a $400 \mathrm{~K}$ potential temperature surface corresponding to the top of the TTL by using the Lagrangian relative humidity history along trajectories with simplified condensation and a water-removal scheme. European Centre for Medium-Range Weather Forecasts (ECMWF) ERA-40 and ERA-Interim were used in the former and latter studies, respectively. Reasonable results were obtained, yielding good agreement with satellite observations of the seasonal cycle and the amount of zonal mean water vapor. However, supersaturation equivalent to 140$180 \%$ (Möhler et al., 2003) or 120-200\% (Murray et al., $2010)$ in relative humidity with respect to ice $\left(\mathrm{RH}_{\mathrm{ice}}\right)$ at a temperature of $240-180 \mathrm{~K}$ is reported from studies based on laboratory experiments. A value of $\mathrm{RH}_{\text {ice }}$ of up to $200 \%$ at $<200 \mathrm{~K}$ has been reported from studies based on aircraft measurements (Krämer et al., 2009). Supersaturation is also observed in environments with ice crystals, reaching approximately $60 \%$ or more in the TTL based on sonde observations (Shibata et al., 2007; Inai et al., 2012; Shibata et al., 2012; Hasebe et al., 2013). These results suggest the need for a quantitative investigation of the efficiency of cold trap dehydration.

To quantify cold trap dehydration and understand stratospheric water vapor variation, we require reliable in situ observations of water vapor in the TTL and the stratosphere with high vertical resolution, in addition to space-borne observations (e.g., Read et al., 2004; Steinwagner et al., 2010; Takashima et al., 2010). To this end, we have been conducting the Soundings of Ozone and Water in the Equatorial Region (SOWER) project using radiosondes, ozonesondes, and chilled-mirror hygrometers in the western tropical Pacific (see Sect. 2; Hasebe et al., 2007, Fujiwara et al., 2010, a companion paper: Hasebe et al., 2013). The data from SOWER campaigns, together with trajectory calculations, indicate that the dehydration associated with quasi-horizontal advection progresses on isentropes from $360 \mathrm{~K}$ to $380 \mathrm{~K}$ and that the threshold of homogeneous nucleation corresponding to approximately 1.6 times saturation proved to be consistent with the observations in the altitude region from the 360 to $365 \mathrm{~K}$ potential temperature surfaces (Hasebe et al., 2013). However, these investigations are limited by the fact that we could not estimate the amount of water vapor removed during advection. To obtain the actual change in water vapor content, it is useful to observe the water vapor of the same air mass more than once at a given interval, employing the match technique applied to ozone depletion by von der Gathen et al. (1995) and Rex et al. (1997, 1998). In the present study, cases in which the same air mass are observed more than once (defined as a "match") are sought from among the SOWER data for the purpose of quantifying "cold trap" dehydration. The application of the match technique may yield an improved understanding of TTL dehydration; however, there are problems to be overcome (see the last part of Sect. 3.2).

This paper reports the results of our water vapor match analyses and provides a discussion on the findings. The remainder of the manuscript is organized as follows. Section 2 introduces the SOWER sounding data, and Sect. 3 describes the methodology used to identify matches in the TTL. In Sect. 4 , the extracted matches are introduced along with evidence regarding the features of dehydration in the TTL. In Sect. 5, the efficiency of the dehydration is discussed. Finally, the conclusions are presented in Sect. 6.

\section{SOWER project and data description}

In the tropical western Pacific/Indonesian region, SOWER campaigns have been conducted during every boreal winter since December 2004 with the intention of accumulating ozone and water vapor data in the TTL for studies on cold trap dehydration. The network of observation stations is designed to capture the air mass advected in the tropical western Pacific/Indonesian region along the mean air flow in the TTL. Cryogenic Frostpoint Hygrometers (CFH; Vömel et al., 2007) and the Snow White hygrometers (SW; Fujiwara et al., 2003; Vömel et al., 2003), equipped with RS80 radiosondes, have been launched in SOWER campaigns to obtain reliable water vapor data in the TTL. In addition, the ozone partial pressure has been measured by the Electrochemical Concentration Cell (ECC) ozonesonde. 
Table 1. Number of water vapor soundings during SOWER campaigns in December 2004, January 2006, January 2007, January 2008, and January 2009. Water vapor was measured using the Snow White (SW) hygrometer or the Cryogenic Frostpoint Hygrometer (CFH).

\begin{tabular}{lccccc}
\hline Obs. Station (lon, lat) & Dec 2004 & Jan 2006 & Jan 2007 & Jan 2008 & Jan 2009 \\
\hline Bandung $\left(107.59^{\circ} \mathrm{E}, 6.89^{\circ} \mathrm{S}\right)$ & $4(\mathrm{CFH})$ & & & & \\
Biak $\left(136.06^{\circ} \mathrm{E}, 1.17^{\circ} \mathrm{S}\right)$ & $3(\mathrm{SW})$ & $12(\mathrm{SW}), 9(\mathrm{CFH})$ & $6(\mathrm{CFH})$ & $7(\mathrm{CFH})$ & $4(\mathrm{CFH})$ \\
Hanoi $\left(105.80^{\circ} \mathrm{E}, 21.01^{\circ} \mathrm{N}\right)$ & $8(\mathrm{SW})$ & $15(\mathrm{SW})$ & $6(\mathrm{CFH})$ & $5(\mathrm{CFH})$ & $4(\mathrm{CFH})$ \\
Kototabang $\left(100.32^{\circ} \mathrm{E}, 0.20^{\circ} \mathrm{S}\right)$ & & $10(\mathrm{SW})$ & $5(\mathrm{CFH})$ & $4(\mathrm{CFH})$ & \\
R/V Mirai $\left(\sim 134.0^{\circ} \mathrm{E}, \sim 7.4^{\circ} \mathrm{N}\right)$ & $15(\mathrm{SW})$ & & & \\
Tarawa $\left(172.92^{\circ} \mathrm{E}, 1.35^{\circ} \mathrm{N}\right)$ & $10(\mathrm{SW})$ & $11(\mathrm{SW}), 2(\mathrm{CFH})$ & $5(\mathrm{CFH})$ & & \\
\hline
\end{tabular}

Table 1 provides an outline of water vapor sounding during the SOWER campaigns in December 2004, January 2006, January 2007, January 2008, and January 2009. During the December 2004 and January 2006 campaigns, the SW was mainly used for water vapor measurements. As its cooling ability is limited, the SW cannot measure water vapor above about $15 \mathrm{~km}$ or about the $360 \mathrm{~K}$ potential temperature level. The CFH is developed by the University of Colorado and the National Oceanic and Atmospheric Association (NOAA) for high-quality measurements of stratospheric water vapor. The uncertainty of CFH measurements is estimated to be approximately $0.5 \mathrm{~K}$ in terms of frost point and less than $9 \%$ in terms of mixing ratio in the TTL (Vömel et al., 2007); the equivalent uncertainties for the SW are somewhat larger. We tentatively assume that the accuracy of water vapor measurements is $\pm 10 \%$ and \pm 1 ppmv. The accuracy of ozonesonde measurements is about $\pm 10 \%$ in the TTL, and the response time is 20-30 s from the troposphere to the stratosphere (Smit et al., 2007). The accuracy of the corresponding background current of ECC is \pm 10 ppbv in the TTL, following Vömel and Diaz (2010).

ECMWF operational analysis data are used to calculate trajectories (see Sect. 3.2). The data are gridded horizontally to a $1.0^{\circ}$ latitude-longitude resolution with 60 (for December 2004 and January 2006) or 91 (for January 2007, 2008, and 2009) model levels in the vertical. The temporal resolution is $6 \mathrm{~h}$. For the detection of convective clouds, the values of equivalent black body temperature $\left(T_{\mathrm{bb}}\right)$ are estimated from satellite (Geostationary Operational Environmental Satellite-9: GOES-9 and Multi-functional Transport Satellite-1 Replacement: MTSAT-1R) IR images (Channel 1: $10.3-11.3 \mu \mathrm{m})$ with latitude-longitude grid spacings of $0.05^{\circ}$ (for $70^{\circ} \mathrm{N}-20^{\circ} \mathrm{S}, 70^{\circ} \mathrm{E}-150^{\circ} \mathrm{E}$ ) or $0.25^{\circ}$ (for $70^{\circ} \mathrm{N}-$ $70^{\circ} \mathrm{S}, 70^{\circ} \mathrm{E}-150^{\circ} \mathrm{W}$ ) with a $1 \mathrm{~h}$ time interval (http://weather. is.kochi-u.ac.jp/). The water vapor mixing ratio and the saturation mixing ratio are estimated from saturation water pressure corresponding to the frost point and atmospheric temperatures, respectively, using the Goff-Gratch equation (Goff and Gratch, 1946; List, 1984).

The SOWER data are analyzed after applying the pressure correction method following Inai et al. (2009) and after compensating for the phase lag in $\mathrm{CFH}$ and SW water measure- ments (see a companion paper to the present study: Hasebe et al., 2013). The quality of the ECMWF analysis field is assessed, based on a comparison with the SOWER data presented by Hasebe et al. (2013).

\section{Water vapor match}

The water vapor matches (i.e., cases in which the water vapor of the same air mass was measured more than once in a given interval) are searched for among the SOWER campaigns (the numbers of soundings are listed in Table 1). This search is conducted using trajectory calculations (Sect. 3.2) followed by intensive screening procedures (Sect. 3.3 and Appendix A). The amount of change in the water vapor mixing ratio is quantified using the matches found after applying these procedures. Before describing the methodology used to find water vapor matches, ozone conservation in the TTL is revisited because this is a key point in the present analysis.

\subsection{Ozone conservation in the TTL}

The odd oxygen $\mathrm{O}_{x}\left(=\mathrm{O}+\mathrm{O}_{3}\right)$ has a very long photochemical lifetime of more than one year in the lower stratosphere (Brasseur and Solomon, 1986) and even longer in the TTL. The photolysis of $\mathrm{O}_{2}$ yields an ozone production rate ranging from about $0.1 \mathrm{ppbv} \mathrm{day}^{-1}$ at the $355 \mathrm{~K}$ potential temperature level to about $2.4 \mathrm{ppbv} \mathrm{day}^{-1}$ at the $400 \mathrm{~K}$ level, depending on altitude (Dessler, 2002). In the stratosphere, where there is little nitrogen oxide, hydrogen oxide acts as a catalyst for ozone. In contrast, in the troposphere, hydrogen oxide reacts with nitrogen oxide, producing odd oxygen. In the TTL, the production rate of odd oxygen is estimated to be 1.0 1.5 ppbv day $^{-1}$ (Wennberg et al., 1998); consequently, the ozone mixing ratio can be regarded as conservative for several days, within the range of uncertainty of ECC measurements (see Sect. 2), as long as the air parcel retains its identity. This conservative property of ozone in the TTL is used to assess the validity of our trajectory calculation (Sect. 3) and to determine the criteria employed in the screening procedure used to identify matches (Sect. 3.3). 


\subsection{Definition of a match}

The values observed by sonde are assumed to represent those of the air parcel within a circle with a radius of $1^{\circ}$ latitude-longitude (i.e., the match radius) centered at the observation station, i.e., the match circle. The circular region covers $\sim 200 \mathrm{~km}$ in diameter. This assumption is supported by the fact that the vertical profiles of variables measured by sonde during ascent and descent agree with each other. Each air parcel is associated with a specific isentropic layer at every $0.2 \mathrm{~K}$ potential temperature level from 350.0 to $360.0 \mathrm{~K}$, and at every $1.0 \mathrm{~K}$ level from 360.0 to $400.0 \mathrm{~K}$. The air parcel is composed of a number of air segments gridded at every $0.1^{\circ} \times 0.1^{\circ}$ latitude-longitude in the circular area defined by the match radius (i.e., match circular area). The air parcel observed by sonde is assumed to be expressed by a set of these air segments. Consequently, the air parcel that may encounter deformation during advection can be estimated along with the uncertainty of the trajectory calculation. Isentropic trajectories are initialized at each segment at $50 \mathrm{~min}$ after the sonde launch. This time delay corresponds to the time taken for the sonde to reach the TTL, i.e., the altitudes of 15 and $18 \mathrm{~km}$ for standard ascending rates of 5 and $6 \mathrm{~m} \mathrm{~s}^{-1}$, respectively.

The isentropic trajectories are calculated by integrating the isentropic wind velocities at a 1-h interval for 10 days by using the ECMWF field (see Sect. 2). Note that the ECMWF data are 6-hourly; hence, the linearly interpolated ECMWF field is used for the 1-hourly integration. Figure 1 is an example of a cluster of forward trajectories on the $370 \mathrm{~K}$ potential temperature surface calculated from whole air segments gridded inside the match circle centered at Tarawa when the sonde reached the TTL (blue and red dots). Those segments included in the match circular area centered at other observations (also at $50 \mathrm{~min}$ after the launch) are defined as match air segments (red dots in Fig. 1) and are assumed to constitute an air parcel of the preliminary match (i.e., a match air parcel). This means that each match air parcel of a preliminary match is defined by a cluster of match air segments included in both the first and second match circular areas. The trajectories are calculated in two ways (forward and backward), and we only consider those cases for which the match air parcels could be defined in both ways. The matches are finally defined after applying the screening processes described below (Sect. 3.3 and Appendix A).

We seek to identify preliminary matches connected by match air parcel in two ways, among all the observations listed in Table 1. Figure 2 shows scatter plots of the mixing ratio for the first and second observations of ozone and water vapor from such preliminary matches. Figure 2 shows that, in addition to the general tendency of higher ozone mixing ratio and lower water vapor mixing ratio at higher altitudes, the data for water vapor are located more to the lower right, indicating a decrease in the water amount (dehydration) during the successive observations; in contrast, the data for ozone

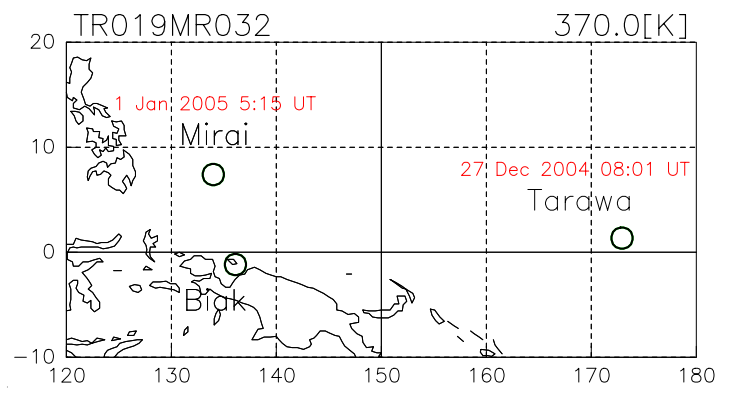

Fig. 1. Example of a cluster of trajectories leaving Tarawa. The blue and red dots are the whole segments calculated from the circled region with a match radius $\left(1^{\circ}\right)$ centered at Tarawa. Only the red dots are included in both the first and second circular areas (i.e., those centered at Tarawa and Mirai, respectively); therefore, they represent a match air parcel (see text for details). The footprints are drawn every $24 \mathrm{~h}$. The air parcel observed over Tarawa on 27 December 2004 (first observation) was observed again (second observation) over Mirai after about 5 days.

are distributed more or less symmetrically with respect to the diagonal.

Before examining the match results in detail, it is confirmed whether the methodology employed to define preliminary matches using trajectories is reliable. The conservative property of ozone in the TTL is used for this assessment. To minimize possible chemical/dynamical effects, we only consider cases for which the time interval between the first and second observations is less than 3 days. This threshold is chosen as the smallest possible time required to obtain the necessary number of samples for the following statistical test. Figure 3 (left) shows a scatter plot of the first versus the second ozone mixing ratio for preliminary matches within a time interval of less than 3 days, superposed on those of all possible pairs (i.e., all possible combinations of observations, sorted by potential temperature and campaign) of the observed ozone mixing ratio on every $1 \mathrm{~K}$ potential temperature surface between 350 and $400 \mathrm{~K}$. Figure 3 (center) shows the correlation coefficients between the first and second ozone mixing ratios for the preliminary matches advected for a period less than 3 days, as a function of the advected potential temperature, and it also shows the correlation coefficients between all the possible pairs of observations. The correlation coefficients are calculated on a logarithmic scale because the ozone mixing ratio shows an exponential increase with altitude. The correlation coefficients for the preliminary matches are significantly higher than those for all the possible pairs, except at the 350 and $380 \mathrm{~K}$ levels. The exemption at the $350 \mathrm{~K}$ level may arise because this level has a relatively high frequency of convective penetration. Consequently, it is necessary to carefully examine whether convection reached the match air parcels (see Sect. 3.3). For the $380 \mathrm{~K}$ level, the ozone mixing ratios measured by the first and second observations roughly agree with each other 

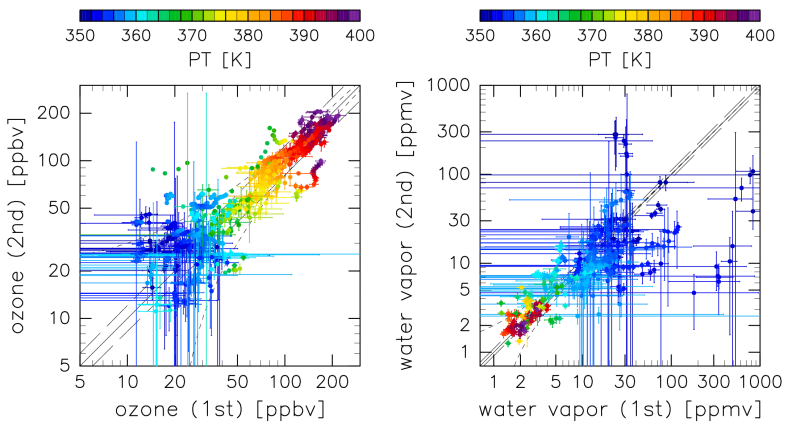

Fig. 2. Scatter plots showing the first (abscissa) versus the second observed values (ordinate) of ozone (left) and water vapor (right) mixing ratios for all preliminary matches connected by match air parcel. Color indicates the potential temperature. Bars in both panels indicate the uncertainties estimated by Hasebe et al. (2013), a companion paper to the present study. The dashed lines oriented parallel to the diagonal in the left panel indicate a difference of $\pm 20 \%$ between the paired observations, and the dotted curves indicate the range of \pm 20 ppbv difference for the paired ozone mixing ratio. These are the thresholds of acceptable difference used in this study (see the last part of Sect. 3.3). Lines in the right panel indicate the accuracy of water vapor measurements; i.e., $\pm 10 \%$ (dashed lines) and \pm 1 ppmv (dotted lines) (see Sect. 2). Note that the water vapor data measured by the Snow White hygrometers are not plotted above $360 \mathrm{~K}$ by their performance problem (see Sect. 2).

within the observational uncertainties for all the preliminary matches. Therefore, the distribution of data in these plots is near-spherical, as shown in the right panel of Fig. 3, thereby yielding a low correlation coefficient.

\subsection{Screening of preliminary matches}

The effectiveness of the methodology used to define preliminary matches is assessed using the ozone mixing ratio as a conserved property. In this section, we seek to screen out false matches before applying the match technique to dehydration in the TTL. The issues addressed by the screening procedure are the representativeness of the match air parcel, the degree of convective penetration, the validity of the isentropic treatment, and the consistency between sonde data and the analysis field.

\subsubsection{Representativeness of match air parcel}

A match air parcel that is composed of match air segments common to the first and second circular areas defined by a match radius (match air segments: see Sect. 3.2) must be representative of the circular area for both observations. Otherwise, the meteorological values measured at the first or second observations cannot be considered as those of a match air parcel. Consequently, it is important to examine the representativeness of the match air parcel. The representativeness is examined based on the temperature difference between the match air segments and whole segments included

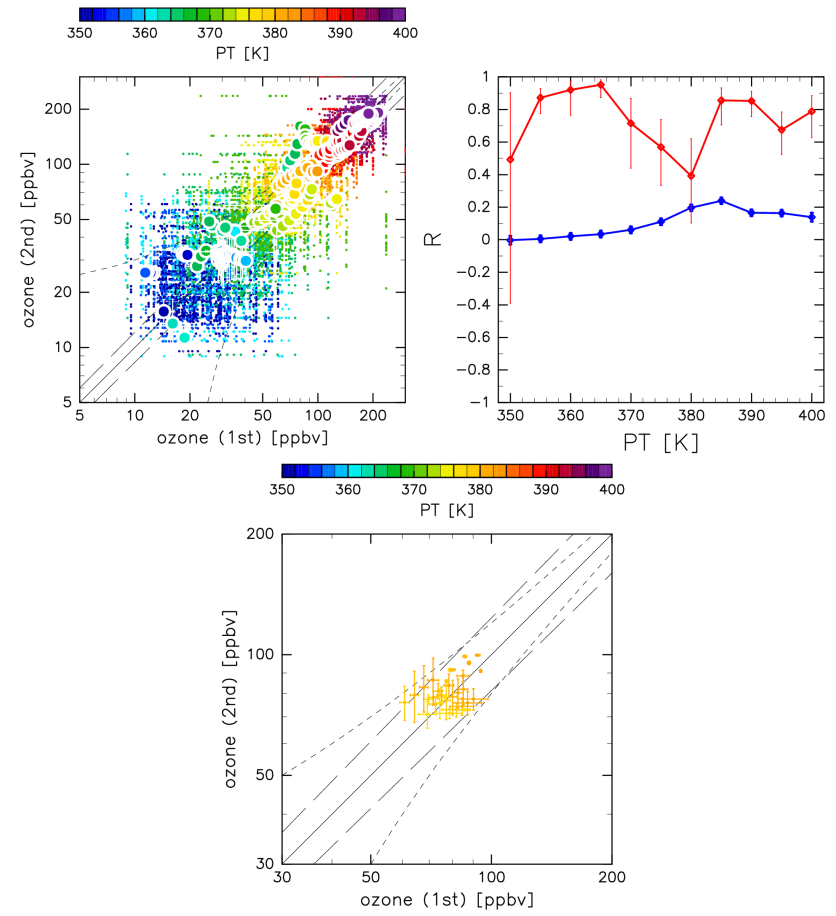

Fig. 3. Left: As for the left panel in Fig. 2 but for preliminary matches for which the time interval between the first and second observations is less than 3 days (large circles). The small dots represent all of the possible paired (see the text for details on the pairing procedure) observations (to reduce clutter, not all data are shown). Center: Correlation coefficients calculated for every $5 \mathrm{~K}$ of potential temperature (with $\pm 2.5 \mathrm{~K}$ bins) for the preliminary matches (red) and for all possible paired observations (blue). Error bars are $90 \%$ confidence intervals. Right: As for the large circles in the left panel but for pairs at altitudes from $377.5 \mathrm{~K}$ to $382.5 \mathrm{~K}$.

in the match circular area (see Appendix A1 for details). This assessment represents the first step of the screening procedure. To move on screening procedures for the remaining problems, we use the "conservative property of ozone" as the second principle. Note that these screening procedures are examined after the first step.

\subsubsection{Convective penetration}

The possible penetration of deep convection is diagnosed by comparing the temperatures of the match air segments $(T)$ and the equivalent blackbody temperature of the underlying cloud $\left(T_{\mathrm{bb}}\right)$. If we assume monotonically decreasing atmospheric temperature with increasing altitude, we may consider that the top of the convection is higher than the altitude of the advected air segment when $T_{\mathrm{bb}}$ minus $T$ ( $\equiv \delta T_{\mathrm{bb}}$ ) is negative. However, it is well known that observed values of $T_{\mathrm{bb}}$ tend to overestimate the cloud top temperature; i.e., underestimate the cloud top altitude (e.g., Sherwood et al., 2004). To address this problem, we add some margin to $\delta T_{\mathrm{bb}}$ values for the diagnosis of convective penetration, as 
described below. If some deep convective clouds reach match air segments that advected in the TTL, some part of the segments will be mixed with the tropospheric air mass, thereby changing the ozone mixing ratio. Thus, the degree of inconsistency between the ozone mixing ratios at the first and second observations of a preliminary match could be used as an indicator of convective mixing. To statistically quantify such inconsistencies, we use the correlation coefficients between the ozone mixing ratios of the first and second observations as a function of the minimum value of $\delta T_{\mathrm{bb}}$ during the advection. In this screening procedure, we adopt $+12 \mathrm{~K}$ as the critical value of the margin for the minimum value of $\delta T_{\mathrm{bb}}$ during the advection (see Appendix A2 for details). This margin corresponds to $2.0-1.2 \mathrm{~km}$ in geometric height for a temperature lapse rate of $6-10 \mathrm{~K} \mathrm{~km}^{-1}$.

\subsubsection{Validity of the isentropic treatment}

Our trajectory calculations are made under the assumption of adiabatic conditions; however, this assumption becomes invalid with increasing advection time, because radiative heating or cooling occurs in the TTL depending on the altitude and cloud conditions. Therefore, we need to establish an upper limit of advection time that ensures the validity of the isentropic treatment and that is acceptable for our match analysis. This assessment is performed using a similar procedure to that for convective penetration (Appendix A2). In other words, the correlation coefficients between the first and second observed ozone mixing ratios of preliminary matches are calculated as a function of the advection time of the match air parcels. We choose 5 days as the threshold of advectiontime length (see Appendix A3 for details).

\subsubsection{Consistency between sonde data and analysis field}

The saturation water vapor mixing ratio (SMR) is estimated from the temperature field of the meteorological objective analysis (ECMWF data are used in this study) along the trajectories. Bias between the sonde data and analysis field would result in erroneous conclusions, including false initialization of trajectory calculations. Inconsistencies between these factors could also arise from small-scale perturbations that are not resolved in the analysis field but are detected by sonde observations. We could reduce such differences by using an isentropic coordinate system, because the air parcels stay on an isentrope even when displaced by small-scale transient waves, such as gravity waves. However, temperature and pressure disturbances associated with the adiabatic motion appear on the isentropes. If the temperature difference between the sonde and analysis field on the same potential temperature surface is large, then the dehydration process cannot be discussed by using both the water vapor mixing ratio measured by sonde and the saturation water vapor mixing ratio estimated from the analysis field. In addition, errors may exist in one or both of the data sets. Therefore, it is im- portant to check for consistency between the sonde data and the analysis field. The consistency is assessed by calculating the correlation coefficients between the first and second ozone mixing ratios of preliminary matches as a function of the difference in temperature between the ECMWF analysis and sonde data. We consider temperature differences of between -4.0 and $5.0 \mathrm{~K}$ for assessing the consistency between the sonde data and analysis field (see Appendix A4 for details). These temperature differences correspond to saturation water vapor mixing ratios of $\sim 1$ to $\sim 6 \mathrm{ppmv}$ in the TTL.

\subsubsection{Other nonspecific factors}

Finally, we re-check that ozone conservation does indeed occur to screen out false matches caused by factors other than those examined above. In practice, the values that are equivalent to twice the uncertainty in ECC measurements (i.e., $\pm 20 \%$ or \pm 20 ppbv; see also Sect. 2) are employed as the threshold of the acceptable difference in the ozone mixing ratio between the first and second observations of each match.

\section{Dehydration estimated from the matches}

The water vapor match in the TTL is defined by trajectory calculations and the screening procedures described in Sect. 3. In this section, we discuss the amounts of water vapor change quantified from the matches. Figure 4 shows scatter plots of the first and second observations of the ozone and water vapor mixing ratios for 107 matches (i.e., all of the matches listed in Appendix B). Note that this number includes matches of observational pairs and potential temperature levels. Among the 107 matches, there are 25 different observational pairs. The values for water vapor are similar between the first and second observations at potential temperature levels above $365 \mathrm{~K}$ (right panel), which suggests that the water vapor mixing ratios show little change. In turn, this means that we found no dehydrated cases in the altitude region where the amount of water vapor entering the stratosphere is controlled. The reasons why no such cases were found are discussed in Sect. 5.4. Below the $360 \mathrm{~K}$ level, almost all of the cases show smaller water vapor amounts for the second observation than for the first. This result represents the first piece of evidence from the water vapor match that appreciable dehydration occurred at these levels. In the following sections, the match cases are analyzed, focusing on hydration and dehydration during advection. Detailed case studies are presented in Sect. 4.1, while statistical features of the dehydration are derived in Sect. 4.2.

\subsection{Detailed case studies}

\subsubsection{Case 1: water conserved}

Figure 5 shows an example of a match between the first (01:42 UT, 11 January 2007) and second observations 

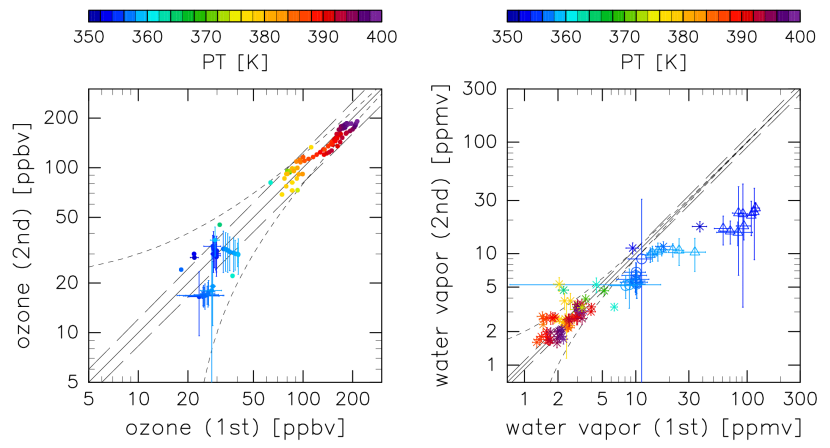

Fig. 4. As for Fig. 2 but for matches identified after applying all of the screening procedures (Sect. 3.3). In the right panel, the axes are modified compared with Fig. 2 and the symbols refer to the hygrometers, i.e., crosses, triangles, and circles indicate paired observations by $\mathrm{CFH}$ and $\mathrm{CFH}$ (for the first and second observations, respectively), $\mathrm{CFH}$ and $\mathrm{SW}$, and $\mathrm{SW}$ and $\mathrm{SW}$, respectively.

(00:37 UT, 15 January 2007), both at Kototabang. The match air parcel advected for approximately 4 days at $371.0 \mathrm{~K}$. The water vapor mixing ratios were measured by $\mathrm{CFH}$, and the values are $3.1 \pm 0.3$ ppmv for the first observation (left-hand red bar in b) and $3.4 \pm 0.3$ ppmv for the second (right-hand red bar). Therefore, the water vapor amount was conserved during the advection. The histories of $\mathrm{RH}_{\mathrm{ice}}, \mathrm{SMR}$, and temperature of the advected match air parcel are shown in Fig. 5. Here, $\mathrm{RH}_{\text {ice }}$ and SMR are calculated using the water vapor mixing ratio of the first measurement, assuming that the water vapor amount remains that of the first measurement. Figure 5a also shows the homogeneous freezing threshold $\left(\mathrm{RH}_{\text {hom }}\right)$ according to Kärcher and Lohmann (2003), which depends on the temperature of the match air parcel; this threshold is considered as the upper limit of $\mathrm{RH}_{\text {ice. }}$. The dots in panel $\mathrm{c}$ are the $T_{\mathrm{bb}}$ values of the underlying atmosphere, corresponding to the advected air parcels. Isentropic backward trajectories, color-coded by the SMR, are shown in Fig. 5e. Figure 5d shows vertical profiles of water vapor observed at the first (orange) and second (red) sonde observations, along with uncertainties. While the SMR of the match air mass, as estimated from the analysis field, reaches about 6.5 ppmv on the two days after the first observation, it is possible that the air mass experienced supersaturation on 11,13 , and 14 January 2007 . The SMR during these periods may have become smaller than the measured water vapor mixing ratio i.e., the $\mathrm{RH}_{\text {ice }}$ exceeds $100 \%$, although it does not exceed $\mathrm{RH}_{\text {hom }}$. This SMR variation along the isentropic trajectories is caused mainly by wave events rather than latitudinal motion (as is the case for the other matches). Because this case is a match on a $371.0 \mathrm{~K}$ potential temperature level, the screening procedure for convective penetration (Appendix A2) is not applied. However, the values of $T_{\mathrm{bb}}$ are appreciably larger than those of the match air mass ( $\leq 195 \mathrm{~K})$. In other words, the values of $T_{\mathrm{bb}}$ are high enough to keep the air mass away from the area of convection.

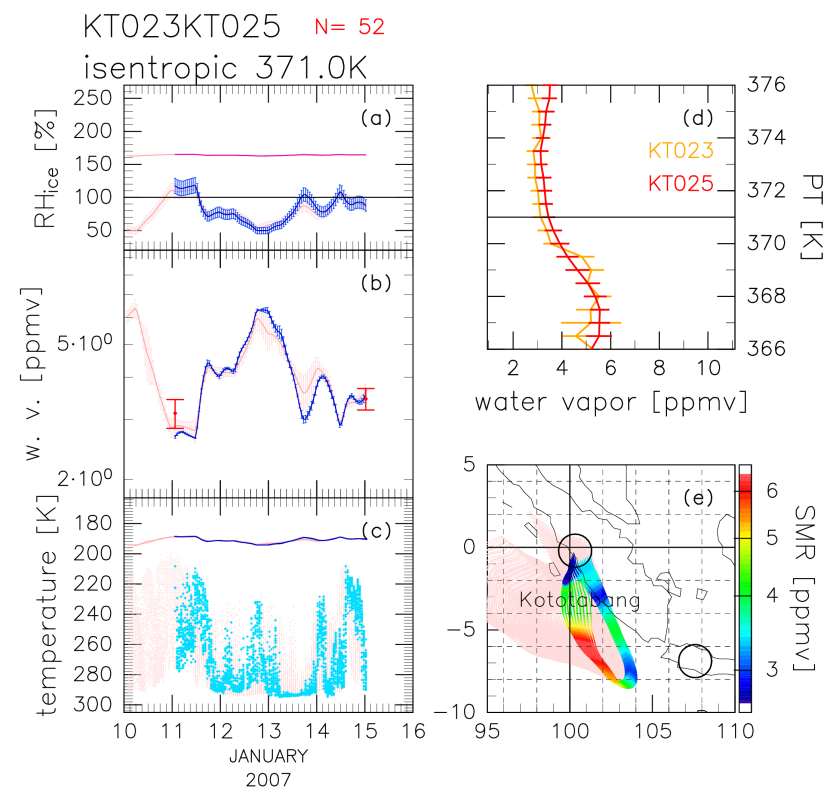

Fig. 5. Meteorological conditions of the match advecting from Kototabang (01:42 UT, 11 January 2007) to Kototabang (00:37 UT, 15 January 2007) on the $371.0 \mathrm{~K}$ potential temperature surface. Those times correspond to the times of observations, i.e., $50 \mathrm{~min}$ after each launch (see Sect. 3.2). Vertical profiles of water vapor measured at the first (orange) and second (red) observations, along with estimates of errors, are shown in (d). The figure shows the time evolutions of (a) relative humidity over ice $\left(\mathrm{RH}_{\mathrm{ice}}\right)$ on the assumption that the water vapor amount is unchanged from the first measurement, along with the uncertainties (blue) and the homogeneous freezing threshold ( $\mathrm{RH}_{\text {hom }}$; purple); (b) saturation water vapor mixing ratio (SMR; blue line); (c) temperature (blue line) and equivalent black body temperature ( $T_{\mathrm{bb}}$; light blue dots); and (e) trajectories of the match air parcel, color coded by SMR history. In (b), the superposed vertical bars in red are the water vapor mixing ratio measured at the match altitude (horizontal black line in (d)). Meteorological data are from ECMWF, and $T_{\mathrm{bb}}$ values are derived from MTSAT-1R/GOES-9 IR images. For (a), (b), (c), and (e) each meteorological value for the match air mass is superposed on that for the whole segments calculated from the circular region centered at the second observation (pink shading).

In this case, it is possible that the air mass was exposed to supersaturation during the advection, as described above, while the water vapor amount of the air mass was conserved. If we assume that nucleation of ice particles was not initiated at any period of the advection, the estimated maximum value of $\mathrm{RH}_{\text {ice }}$ during the advection is $124 \%$ with an uncertainty of $-17 \% /+16 \%$ when the SMR becomes the minimum value $\left(\mathrm{SMR}_{\min }\right)$, taking a value of $2.6 \mathrm{ppmv}$.

\subsubsection{Case 2: dehydrated}

Figure 6 is the same as Fig. 5 but for the match case from Tarawa (03:48 UT, 13 December 2004) to Mirai (05:17 UT on 16 December 2004) on the $356.4 \mathrm{~K}$ potential temperature 
surface with an advection time of about 3 days. The water vapor mixing ratios are $10.2 \pm 1.9 \mathrm{ppmv}$ (the first observation) and $5.3 \pm 1.3 \mathrm{ppmv}$ (the second), indicating some dehydration during advection.

In this altitude region, we find that the ECMWF temperature has a cold bias of $2 \mathrm{~K}$ on the isentropic surfaces ranging from 355 to $360 \mathrm{~K}$ (Hasebe et al., 2013). For all subsequent analyses, this bias is taken into account when estimating SMR along the trajectories in this altitude region. The time evolution of SMR has small perturbations with an $\mathrm{SMR}_{\min }$ value of $8.9 \mathrm{ppmv}$ at about $5 \mathrm{~h}$ before the second observation. At this time, the temperature of the air mass is $197.4 \mathrm{~K}$. This $\mathrm{SMR}_{\min }$ value is smaller than the water vapor mixing ratio of the first observation. The $\mathrm{RH}_{\text {ice }}$ during advection indicates a maximum value of $\mathrm{RH}_{\text {ice }}$ of $115 \%$ with an uncertainty of $\pm 21 \%$. Because the match air mass is dehydrated, this case indicates that ice nucleation must have started before the $\mathrm{RH}_{\text {ice }}$ reached $115 \%$. As this value is much smaller than $\mathrm{RH}_{\text {hom }}$, it might correspond to the heterogeneous freezing threshold. A comparison between the second water vapor observation and $\mathrm{SMR}_{\min }$ suggests that dehydration continued until $\mathrm{RH}_{\text {ice }}$ reached $60 \%$ with an uncertainty of $\pm 16 \%$. If the dehydration does not proceed to less than $100 \%$ of $\mathrm{RH}_{\text {ice }}$, the temperature of the air mass must have decreased by about $3.2 \mathrm{~K}$ from the temperature $197.4 \mathrm{~K}$, when the air mass is coldest, falling to $194.2 \mathrm{~K}$ on the $356.4 \mathrm{~K}$ potential temperature surface.

Information on the existence of ice particles is important when interpreting the $\mathrm{RH}_{\text {ice }}$ value in terms of dehydration efficiency. For this purpose, we use the backscattering coefficients observed by lidar installed on the research vessel Mirai. According to Fig. 3 of Fujiwara et al. (2009), cirrus clouds were observed at around the $355 \mathrm{~K}$ potential temperature level (about $15.5 \mathrm{~km}$ height) when the second observation of this match was made. The cirrus clouds may have resulted from dehydration of the match air mass shown in Fig. 6, meaning that the match air mass may have experienced a temperature below $194.2 \mathrm{~K}$.

\subsubsection{Case 3: dehydrated}

Figure 7 is the same as Fig. 5 but for the match from Biak (09:46 UT, 15 January 2008) to Hanoi (06:45 UT, 20 January 2008 ) on the $350.4 \mathrm{~K}$ potential temperature surface with an advection time of about 5 days. The observed water vapor mixing ratios are $37.7 \pm 5.6 \mathrm{ppmv}$ (the first observation) and $17.5 \pm 1.9$ ppmv (the second), indicating appreciable dehydration during advection.

This match air parcel has also experienced an SMR value smaller than the first observed water vapor mixing ratio. The $\mathrm{SMR}_{\min }$ value of $15.1 \mathrm{ppmv}$ is estimated just before 00:00 UT on 18 January 2008 (2.5 days after the first observation). The $\mathrm{RH}_{\text {ice }}$ shows a maximum value of $249 \%$, far exceeding the $\mathrm{RH}_{\text {hom }}$, with an uncertainty of $-37 \% /+38 \%$ during the advection. Therefore, the match air parcel is ex-

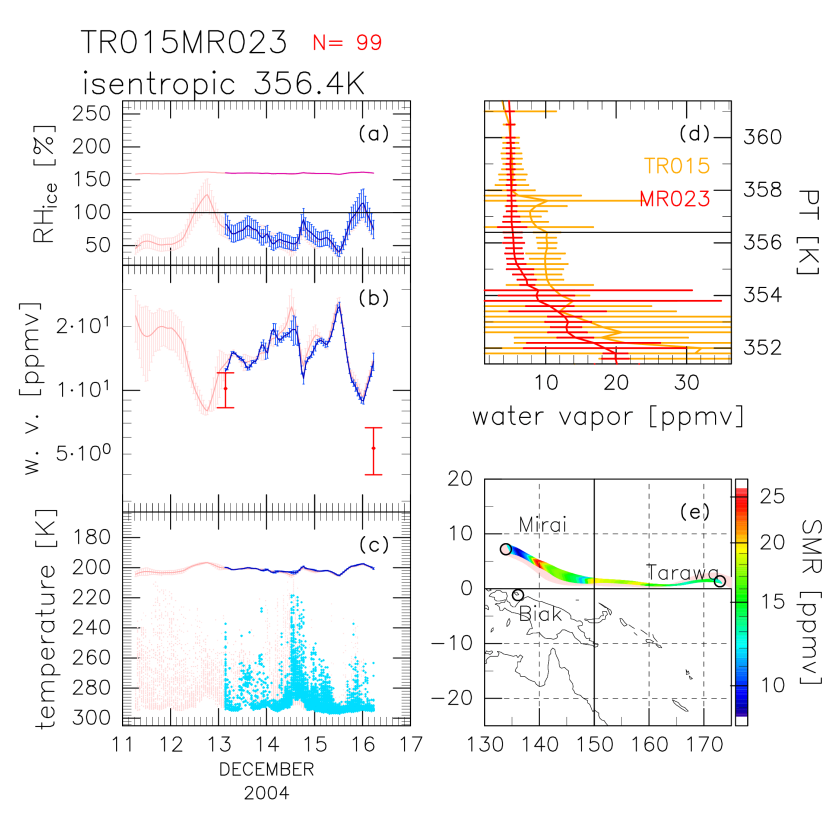

Fig. 6. As for Fig. 5 but for the match that advected from Tarawa (03:48 UT, 13 December 2004) to Mirai (05:17 UT on 16 December 2004 ) at the $356.4 \mathrm{~K}$ potential temperature surface with an advection time of about 3 days.

pected to be dehydrated. The alternative comparison, between the water vapor mixing ratio measured at the second observation and the $\mathrm{SMR}_{\min }$ value, yields an $\mathrm{RH}_{\text {ice }}$ value of $116 \%$ with uncertainty of $\pm 12 \%$ when the SMR attains the minimum value. This result suggests that the air mass was dehydrated down to $116 \% \mathrm{RH}_{\text {ice }}$ when the air mass experienced $\mathrm{SMR}_{\min }$. The SMR history of this match air mass and the water vapor mixing ratios observed at the first and second observations are discussed again in Sect. 5, along with a description of the procedure for estimating the efficiency of dehydration.

\subsubsection{Case 4: hydrated}

While some of the detected matches showed reduced or conserved water vapor amount, others showed an increase, probably due to convective penetration. Although a screening procedure for convective penetration was applied, it was not applied above the $370 \mathrm{~K}$ level, as explained in Appendix A2. An example of a hydrated case is provided in Fig. 8, which shows the vertical profiles of frost point temperature (red), temperature (black), and ozone mixing ratio (green) at the second observation of a match. This match is identified at altitudes ranging from potential temperatures of 378 to $383 \mathrm{~K}$. The thin humid layer around $380 \mathrm{~K}$ shown in Fig. 8 may result from the penetration of some deep convection. A similar water vapor profile, affected by convective penetration, has been reported by Khaykin et al. (2009) during the monsoon season over West Africa. These authors investigated the features of water vapor and ozone profiles in the case 


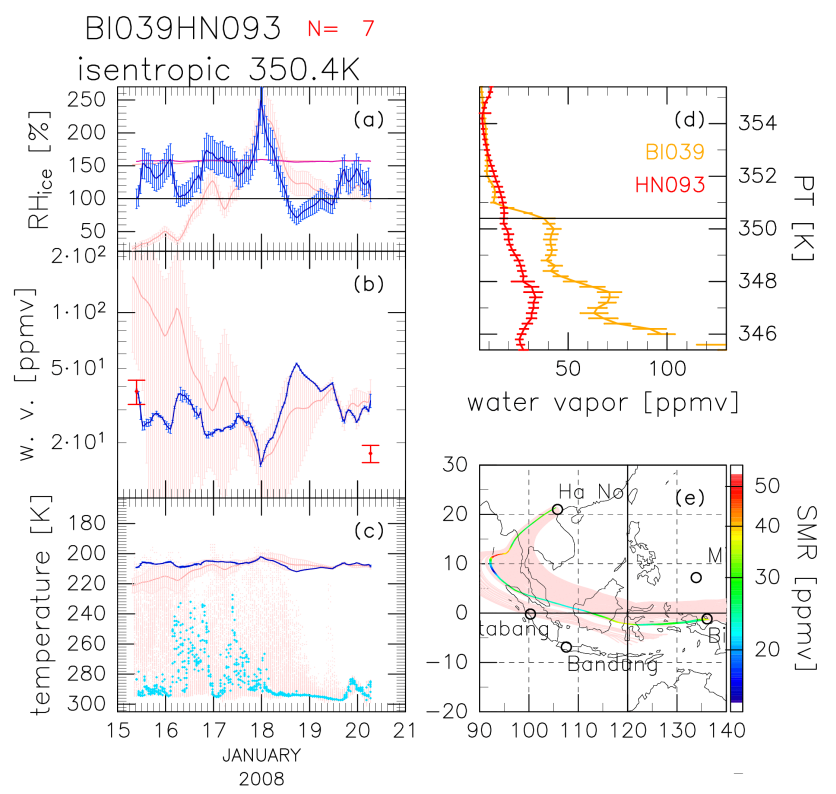

Fig. 7. As for Fig. 5 but for the match that advected from Biak (09:46 UT, 15 January 2008) to Hanoi (06:45 UT, 20 January 2008) at the $350.4 \mathrm{~K}$ potential temperature surface with an advection time of about 5 days.

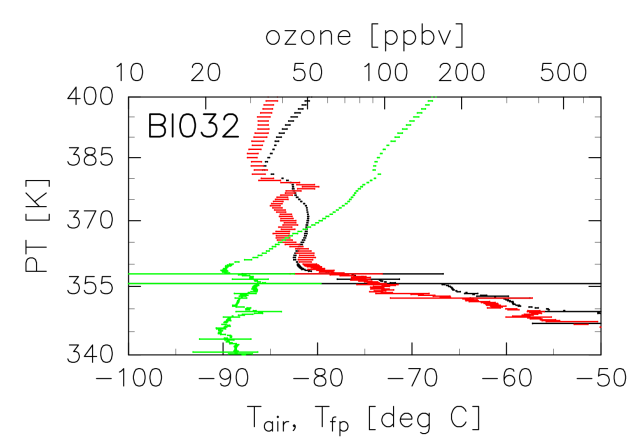

Fig. 8. Vertical profiles of frost point temperature (red), temperature (black), and ozone mixing ratio (green) observed at Biak (04:35 UT, 16 January 2007). The horizontal bars show the uncertainties of sonde measurements estimated by Hasebe et al. (2013) (see appendix A in their paper).

that deep convection penetrated into the TTL. However, it is puzzling in our case that the ozone mixing ratio (green) in Fig. 8 shows an increase with increasing altitude, reaching as high as $80 \mathrm{ppbv}$ at the hydrated layer. Such a large amount of ozone is inconsistent with the idea that the air mass originated from convection (Folkins et al., 2002). One possible explanation of the puzzling correlation between water vapor and the ozone profiles is that some convection is injected into an altitude above $380 \mathrm{~K}$ where the ozone profile has a local minima at the cold point, after which only ice particles fall to below the $380 \mathrm{~K}$ level and evaporate there.

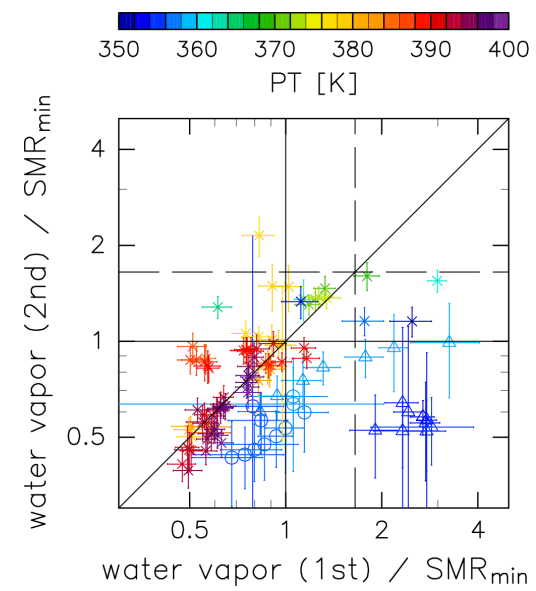

Fig. 9. Scatter plot of ratios of the water vapor mixing ratio at the first observation to $\mathrm{SMR}_{\min }$ estimated from the SMR history during advection (abscissa), versus ratios of the water vapor mixing ratio at the second observation to $\mathrm{SMR}_{\min }$ (ordinate), for all matches. Colors indicate the altitude (potential temperature). Symbols refer to the hygrometers (see the caption to Fig. 4). The dashed black lines indicate the approximate homogeneous freezing threshold $(=1.65)$.

\subsection{Statistical features of dehydration}

In Sect. 4.1, we used the matches to estimate the upper limit of $\mathrm{RH}_{\text {ice }}$ before ice condensation starts. This limit was derived from the ratio of the first observed water vapor mixing ratio to $\mathrm{SMR}_{\min }$, as discussed using the dehydrated cases. In this section, the statistical features of the dehydration in the TTL are examined.

Figure 9 shows a scatter plot of the ratio of the water vapor mixing ratio at the first observation to $\mathrm{SMR}_{\min }$ estimated from the SMR history during the advection (abscissa), versus the ratio of the water vapor mixing ratio at the second observation to $\mathrm{SMR}_{\min }$ (ordinate), for all matches. The colors indicate potential temperatures. The cases for which the water amount was conserved plot on the diagonal, while dehydrated cases plot in the lower right part of the figure. The match cases for which the first (the second) water vapor mixing ratio coincides with $\mathrm{SMR}_{\min }$ appear on the black line oriented vertically (horizontally).

The matches above $370 \mathrm{~K}$ potential temperature plot near the diagonal line and in a square-shaped region at lower left. These features indicate that the air mass of these cases was never saturated; consequently, the water vapor amounts were conserved. Some cases plot to the upper left of the diagonal, and these hydrated cases may be attributed to the injection of ice particles associated with the convective process and evaporation, as described in Sect. 4.1. At altitudes below the cold point in particular, the hydration process is not only convective penetration but also the sedimentation of ice particles resulting from the upper (i.e., colder) level of cold point dehydration and from evaporation of the particles (e.g., 
Jensen and Pfister, 2004). The latter hydration process could not be detected in the present study, and is therefore not considered further. The neglecting of this process is unlikely to significantly affect the results, because the absolute amount of water vapor generally shows an exponential decrease with decreasing temperature.

Below the $360 \mathrm{~K}$ level, on the other hand, many match pairs plot in the lower-right part of Fig. 9. Such air parcels encounter cold events in which $\mathrm{SMR}_{\min }$ is smaller than the first observed water vapor mixing ratio (right-hand side of the vertical line), and are eventually dehydrated (lower right, near the diagonal).

It seems that the dehydration process differs between the lower and upper parts of the TTL.

The upper limit of $\mathrm{RH}_{\text {ice }}$ before ice nucleation starts and that with ongoing dehydration has been estimated by using all matches in which the match air parcel experienced saturation or supersaturation and then became dehydrated (i.e., cases in which the first observed water vapor amount is larger than both the second observed water vapor amount and $\mathrm{SMR}_{\min }$ ) in the altitude region from 350 to $360 \mathrm{~K}$. For those matches in which the maximum of $\mathrm{RH}_{\text {ice }}$ during the advection exceeds the $\mathrm{RH}_{\text {hom }}$, the value of $\mathrm{RH}_{\text {hom }}$ is used except for $\mathrm{RH}_{\text {ice }}$ because it is considered the upper limit of supersaturation. A few cases experienced dehydration and supersaturation above $360 \mathrm{~K}$; however, the number of cases is too small to enable a meaningful statistical analysis. The mean ratio of the water vapor mixing ratio at the first observation against $\mathrm{SMR}_{\min }$ is calculated to be $146 \pm 19 \%(1 \sigma)$ for cases dehydrated below $360 \mathrm{~K}$. The mean ratio of the water vapor mixing ratio at the second observation against $\mathrm{SMR}_{\min }$ is $75 \pm 23 \%(1 \sigma)$. The $1 \sigma$ refers to the spread of results for different matches. These values suggest that the upper limit of $\mathrm{RH}_{\text {ice}}$, before ice nucleation starts, is about $146 \%$, while dehydration continues until $\mathrm{RH}_{\text {ice }}$ reaches, statistically, about $75 \%$ in the altitude region from 350 to $360 \mathrm{~K}$. The implications of these values are discussed in Sect. 5.2.

\section{Discussion}

In general, tropical convective activities lift air masses from the planetary boundary layer to the level of neutral buoyancy. Above the approximately $400 \mathrm{~K}$ potential temperature surface, the Brewer-Dobson circulation lifts air masses to the deeper stratosphere. In the TTL, existing between these two regions, the air mass moves horizontally with a gradual ascent balancing radiative heating. Rare detrainment of deep convective clouds may occur throughout the TTL, and this is likely to influence the water vapor concentrations of the TTL to some degree. The local temperature minimum in the TTL (approximately $370 \mathrm{~K}$ ) over the western Pacific leads to cold trap dehydration. This dehydration process is considered to be the most important process controlling the amount of water vapor entering the stratosphere (e.g., Holton and Get- telman, 2001; Hatsushika and Yamazaki, 2003; Fueglistaler et al., 2009; Hasebe et al., 2013).

A companion paper to the present study, Hasebe et al. (2013), conducted a statistical analysis of the relationship between the observed water vapor mixing ratio and the minimum saturation water vapor mixing ratio that the air mass experienced in the past five days. The results showed that cold trap dehydration progressed with slow diabatic ascent from $360 \mathrm{~K}$ to $380 \mathrm{~K}$. In the present study, it is unfortunate that dehydrated air masses are rare in the altitude region around the $370 \mathrm{~K}$ potential temperature surface (the reasons for this are discussed in Sect. 5.4); nonetheless, dehydration associated with horizontal advection is evident in the lower part of the TTL, as revealed by the match technique. The following section discusses the applicability of the screening parameters examined in Sect. 3.3, the two $\mathrm{RH}_{\text {ice }}$ values evaluated as the ratios of the first- and second-observed water vapor mixing ratios against $\mathrm{SMR}_{\min }$ in the previous section, the efficiency of dehydration in the lower TTL, and the lack of dehydrated cases near the cold point.

\subsection{Applicability of screening parameters}

In this study, several numerical values of the screening criteria were examined and estimated as screening parameters (Sect. 3.3 and Appendix A). Here, we consider whether the parameters estimated in this study could be applied to other TTL studies that consider different regions or seasons.

From 2004, the SOWER campaigns have been conducted in the western Pacific in boreal winter. The spatial-temporal region is convectively active and the TTL is the coldest. The active convection results in a condition in which subgrid-scale perturbations occur, resulting in inconsistencies between meteorological profiles observed by sonde and the meteorological analysis (objective analysis) field, as well as small-scale temperature perturbations on each isentrope in the TTL. Consequently, it is possible that the criteria for "consistency between sonde data and analysis field" (i.e., $-4.0 \mathrm{~K} \leq \delta T \leq 5.0 \mathrm{~K}$; see Appendix A4) and "representativeness of the match air parcel" (i.e., the difference between the match air segments and the whole segments inside the match circle is within $[-2.0,2.0] \mathrm{K}$; see Appendix A1) can be stricter (i.e., these acceptable ranges can be narrowed down) when these criteria apply to a calmer region or season (when small-sale perturbations are less active) than those of the present study. The coldness in the TTL results in a condition in which cirrus clouds are frequently formed in the TTL, resulting in diabatic uplift of the air mass by radiative heating (e.g., Corti et al., 2006). The clouds make it difficult to track the air parcel because isentropic trajectories are used in this study. Therefore, it is possible that the criterion for "validity of the isentropic treatment" (i.e., advection time of less than 5 days; see Appendix A3) can be relaxed in other spatialtemporal regions where cirrus clouds are rarely formed. 
According to Hamada and Nishi (2010), the relationship between $T_{\mathrm{bb}}$ value and cloud top height is largely independent of the observation season; however, it depends on the satellite zenith angle. The SOWER campaign sites are located from approximately $100^{\circ} \mathrm{E}$ to $170^{\circ} \mathrm{E}$ and the nadir of MTSAT-1R/GOES-9 is approximately $140^{\circ} \mathrm{E}$; consequently, the zenith angles at SOWER campaign sites range from $0^{\circ}$ to $40^{\circ}$. This angle may be even larger for the "match air parcels" (Sect. 3.2). Even so, the difference between average cloud top height in the nadir region and in the region with satellite zenith angle around $50^{\circ}$ is less than $1 \mathrm{~km}$. This difference is not statistically significant, according to Fig. 7 in Hamada and Nishi (2010). Therefore, the criterion for "convective penetration" (i.e., $<\delta T_{\mathrm{bb}}>_{\min } \geq 12 \mathrm{~K}$; see Appendix A2) may be applied to studies in different regions and seasons. However, the numerical value of the criterion should be re-evaluated when using $T_{\mathrm{bb}}$ data with different resolution from that of MTSAT-1R/GOES-9, such as data observed by MODerate resolution Imaging Spectroradiometer (MODIS).

\subsection{Relative humidity before ice nucleation and after dehydration in the lower TTL}

As described in Sect. 4.2, the upper limit of $\mathrm{RH}_{\text {ice }}$ before the initiation of condensation is estimated to be $146 \pm 19 \%$ $(1 \sigma)$ from matches, indicating dehydration in the altitude range from 350 to $360 \mathrm{~K}$ in potential temperature. These estimates are based on a meteorological analysis field having finite temporal-spatial resolution; hence, sub-grid-scale variations are not taken into account. It is possible that the air is instantaneously exposed to a higher degree of supersaturation than that estimated in the present study. Comparisons of the second observed water mixing ratio and $\mathrm{SMR}_{\min }$ yield an estimate of the air masses being dehydrated to the level of $\mathrm{RH}_{\text {ice }}$ reaching $75 \pm 23 \%(1 \sigma)$. If we take this result at face value, TTL dehydration could proceed beyond the apparent saturation level, although the estimated uncertainty is too large to be certain of this possibility. Statistically this level of significance is not large enough to claim that the threshold is below $100 \%$. Therefore, although the derived value is far from $100 \% \mathrm{RH}_{\text {ice }}$, the significance is not strong enough to claim that ice growth happens at subsaturated conditions. However, one possible explanation of ice growth under unsaturated conditions is that the value of our estimate is affected by sub-grid-scale temperature perturbations that could not be resolved in our analysis, as described above. For example, temperature variation of $2 \mathrm{~K}$ is sufficient to create RHice variation of up to $30 \%$.

Some studies (e.g., Voigt et al., 2008; Chepfer and Noel, 2009) raised the possibility that nitric acid trihydrate (NAT; $\mathrm{HNO}_{3}-3 \mathrm{H}_{2} \mathrm{O}$ ) exists in the TTL. Crutzen and Arnold (1986) show that the critical temperature of NAT formation is higher than that of ice formation. In such a case, although the interpretation of our results would become even more complex, it may be possible that the dehydration could progress to a state of $\mathrm{RH}_{\text {ice }}$ less than $100 \%$ until the NAT saturation state, due to the absorption of water vapor into NAT particles. We calculated the saturation water vapor mixing ratio over a surface of NAT (SMR $\mathrm{SAT}_{\mathrm{NA}}$ ) and the minimum value of SMR $\mathrm{NAT}_{\mathrm{N}}$ along

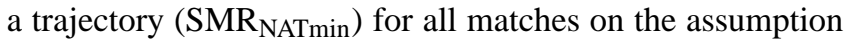
that $\mathrm{HNO}_{3}$ mixing ratio is $1 \mathrm{ppbv}$. If we use $\mathrm{SMR}_{\mathrm{NATmin}}$ instead of $\mathrm{SMR}_{\min }$, then the mean ratio of the water vapor mixing ratio at the second observation against $\mathrm{SMR}_{\mathrm{NATmin}}$ is $91 \pm 42 \%(1 \sigma)$. This result could potentially support the possibility of dehydration in air subsaturated over ice. However, the abundance of $\mathrm{HNO}_{3}$ is much smaller than that of $\mathrm{H}_{2} \mathrm{O}$ in the TTL. Therefore, even if NAT particles were formed and fully removed from the air mass, they would remove only a few ppbv of water vapor, which is insignificant with respect to dehydration.

Given that our estimates of the initiation and termination of ice nucleation have large uncertainties, there is little that we can infer from the results. However, by accumulating more matches with improved accuracy of both observations and trajectory calculations, it would be possible to improve our understanding of the conditions required for ice nucleation.

\subsection{Estimation of the efficiency of dehydration in the lower TTL}

The efficiency of dehydration depends on various factors, including the concentration and size distribution of cloud condensation nuclei, the duration of a cold event, and the degree of supersaturation of the air mass. Although a complete set of observations is unavailable, our matches would provide some useful constraints on the processes of dehydration in the TTL. We attempt to model the efficiency of dehydration using two terms: the critical value of $\mathrm{RH}_{\text {ice }}$ that enables ice nucleation $\left(\mathrm{RH}_{\text {cri }}\right)$ and the dehydration rate as a gross measure of the nucleation rate and the gravitational removal of ice particles. Here, the dehydration rate is defined as the relaxation time (e-folding time: $\tau$ [hour]) taken by a supersaturated air parcel to approach the saturation state by the nucleation and removal of ice particles. These two parameters, $\mathrm{RH}_{\text {cri }}$ and $\tau$, are estimated as follows. Suppose that an air mass with the water vapor mixing ratio of the first observation advects along the trajectories. If the parameters $\mathrm{RH}_{\text {cri }}$ and $\tau$ are given, we would describe the time evolution of the water vapor mixing ratio for each advected air parcel. For example, in the case of $\mathrm{RH}_{\mathrm{cri}}=110 \%$, the air mass starts to be dehydrated, with the rate of dehydration depending on $\tau$ when the $\mathrm{RH}_{\text {ice }}$ exceeds $110 \%$. Such calculations are repeated for a given value of $\mathrm{RH}_{\text {cri }}$ (values of $100 \%, 110 \%$, $130 \%$, and $165 \%$ ) to identify the value of $\tau$ that is consistent with the second observation of water vapor. These values of $\mathrm{RH}_{\text {cri }}$ correspond to the water saturation, heterogeneous freezing of efficient ice nuclei, heterogeneous freezing of less efficient ice nuclei, and approximate homogeneous freezing thresholds. Here, $\tau$ is assumed to be independent of 


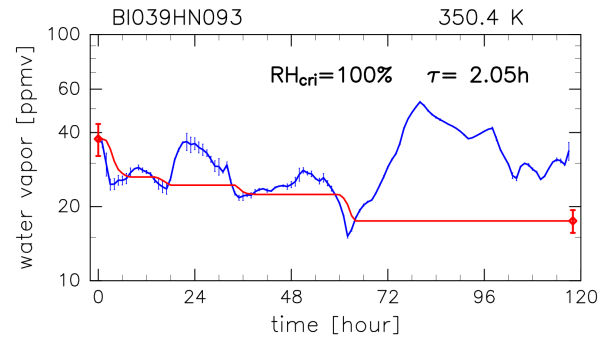

(a)

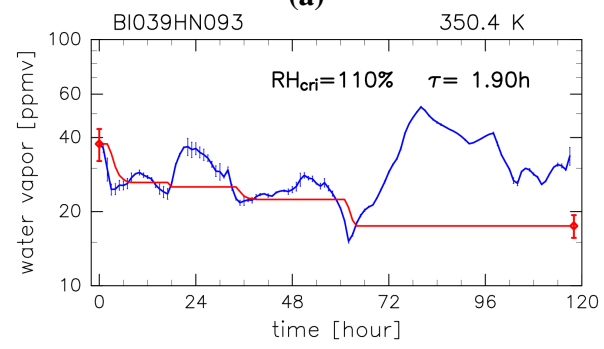

(b)

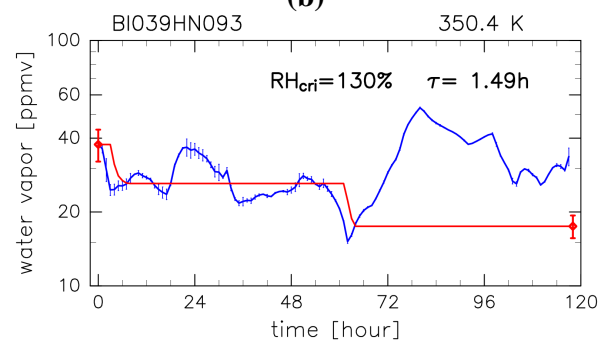

(c)

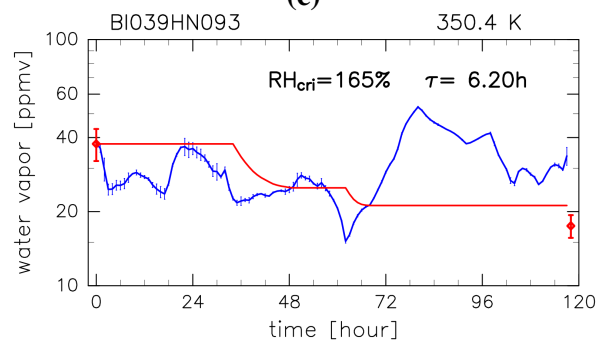

(d)

Fig. 10. Dehydration scenarios showing the time evolution of the water vapor mixing ratio of the air mass (red line) and exposed SMR (blue line) estimated from the match case shown in Fig. 7. The value of $\tau$ stated in each panel is the estimated relaxation time of condensation for the assumed values of $\mathrm{RH}_{\text {cri }}$, which are (a) $100 \%$, (b) $110 \%$, (c) $130 \%$, and (d) $165 \%$.

temperature and pressure, and it is assumed to have a fixed value during advection.

Figure 10 shows examples for such calculations corresponding to the match air parcel shown in Fig. 7. For a $\mathrm{RH}_{\text {cri }}$ value of $100 \%$, it is evident that the air mass is dehydrated every time the SMR becomes smaller than the water vapor it contains (Fig. 10a). On the other hand, dehydration does not occur in other cases until some additional cooling is applied. In most cases (but not all), we find a unique value of $\tau$ that best fits the second water vapor observation for any given value of $\mathrm{RH}_{\mathrm{cri}}$. Of note, no value of $\tau$ yields the second observed water vapor mixing ratio for a $\mathrm{RH}_{\mathrm{cri}}$ value of near $165 \%$ (Fig. 10d).

The statistical features of the efficiency of dehydration are analyzed in terms of the values of $\mathrm{RH}_{\mathrm{cri}}$ and $\tau$. Table 2 shows the variation in $\tau$ for each $\mathrm{RH}_{\mathrm{cri}}$ value derived from matches. $\tau$ shows a general decrease with increasing $\mathrm{RH}_{\text {cri }}$, although there are exceptions. Below $360 \mathrm{~K}$, the mean values of $\tau$ are approximately $1.0 \mathrm{~h}$ in the cases supposing a heterogeneous threshold, regardless of $\mathrm{RH}_{\mathrm{cri}}$. These values are much shorter than the typical timescale of horizontal advection in the TTL, and are shorter than the time interval of available ECMWF data. Therefore, it is suggested that cold trap dehydration is quite efficient in the lower levels of the TTL. On the other hand, values of $\tau$ are estimated to be more than $100 \mathrm{~h}$ at $369 \mathrm{~K}$ for the $\mathrm{RH}_{\text {cri }}$ values other than $165 \%$. This raises the possibility that the value of $\tau$ increases in the upper levels of the TTL.

Naturally, the species of aerosols control the cloudmicrophysical behavior of the atmosphere. However, the value of $\tau$ was calculated for an assumed $\mathrm{RH}_{\text {cri }}$ and after the beginning of ice nucleation, thereby depending on the value of assumed $\mathrm{RH}_{\mathrm{cri}}$. In addition, the value of $\tau$ is largely independent of the value of $\mathrm{RH}_{\mathrm{cri}}$, as shown in Table 2 . Therefore, the estimate of $\tau$ is unlikely to show marked changes with the background aerosol condition. However, it may be sensitive to the altitude range, as indicated by the facts that values of $\tau$ are estimated to be more than $100 \mathrm{~h}$ at $369 \mathrm{~K}$ and that dehydrated cases are lacking near the cold point (the possible reason for this is discussed in Sect. 5.4).

\subsection{Lack of dehydrated cases near the cold point}

Sixteen matches were found in the altitude region from $370 \mathrm{~K}$ to $380 \mathrm{~K}$ (eight different observational pairs are included in this number). However, there are no dehydrated cases that exceed the uncertainty of water vapor measurements. In contrast, two hydrated cases exceed the uncertainty, as described in last part of Sect. 4.1. Here, we examine one possible reason for the lack of dehydrated cases around the cold point altitude. The microphysical behavior of cirrus cloud particles in the TTL is largely unknown. Even so, we presume that the dehydration associated with horizontal advection becomes less efficient with reduced water vapor and temperature, based on previous results (e.g., Koop et al., 2000; Murray et al., 2010). In this analysis, only those observational pairs for which the advection time (from the first to the second observation) is less than 5 days are identified as match cases, in order to assure the reliability of the trajectory (see Appendix A3). If the time required to complete the dehydration around $370 \mathrm{~K}$ was longer than 5 days, any dehydrated cases would not be found in this analysis at such an altitude. In fact, it is suggested that the relaxation timescale at $369 \mathrm{~K}$ was much larger than those at lower levels (see Sect. 5.3). In such a case, it is necessary to reduce the uncertainty of the 
Table 2. Dehydration rate measured by the relaxation time $\tau$ [hour] as a function of the critical value of $\mathrm{RH}_{\mathrm{ice}}$ that enables ice nucleation $\mathrm{RH}_{\text {cri }}$, derived from matches. The values of mean $\tau$ and the standard deviation are indicated in the altitude region from $350 \mathrm{~K}$ to $360 \mathrm{~K}$. The numbers of matches are shown in parentheses.

\begin{tabular}{ccccc}
\hline Altitude $[\mathrm{K}]$ & $\mathrm{RH}_{\text {cri }} 100 \%$ & $\mathrm{RH}_{\text {cri }} 110 \%$ & $\mathrm{RH}_{\text {cri }} 130 \%$ & $\mathrm{RH}_{\text {cri }} 165 \%$ \\
\hline 369 & $110(1)$ & $110(1)$ & $110(1)$ & $17(1)$ \\
361 & $16(1)$ & $16(1)$ & $16(1)$ & $14(1)$ \\
$350-360$ & $1.0 \pm 1.2(4)$ & $1.0 \pm 1.2(4)$ & $0.9 \pm 1.1(4)$ & $0.5 \pm 0.9(3)$ \\
\hline
\end{tabular}

trajectory calculation in order to track the air mass for long enough to enable the dehydration to reach completion.

The ice number concentration and the particle size of cirrus clouds in the TTL are reported to be approximately $100 \mathrm{~L}^{-1}$ and $10 \mu \mathrm{m}$, respectively (e.g., Shibata et al., 2007; Krämer et al., 2009). Such a water content is equal to approximately $0.5-1.0 \mathrm{ppmv}$ of the water vapor mixing ratio in the TTL environment. According to Pruppacher and Klett (1997), an ice particle of $10 \mu \mathrm{m}$ in size requires approximately $8 \mathrm{~h}$ to fall through $1 \mathrm{~km}$. However, these values correspond to cirrus clouds with a relatively thick optical depth; in contrast, the ice particles in optically thin cirrus clouds are much smaller than $10 \mu \mathrm{m}$. For example, Pruppacher and Klett (1997), stated that a particle of $1 \mu \mathrm{m}$ in size (the existence of such small ice particles was suggested by Iwasaki et al., 2007) requires approximately 20 days to fall through $1 \mathrm{~km}$. If the dehydration process around the cold point results in the formation of such small particles, then the period required for ice removal is too long to enable tracking of the air parcel. Unfortunately, such a long-running trajectory would be difficult to calculate accurately and it would be inappropriate for match analysis; in addition, it could be used to estimate the global-scale distribution of water vapor, as shown by Fueglistaler et al. (2004) and Ploeger et al. (2011).

If the lack of dehydrated cases around the cold point reflects the fact that the dehydration timescale is too long, one effective approach to resolve this problem would be to reduce the uncertainty in water vapor measurements and to observe the size distribution and concentration of ice particles together with the amount of water vapor. Because the default soundings in previous SOWER campaigns did not include any sensors for particles, we could not estimate the total water content in which the air mass has ice particles. In addition, for the campaign region and period (i.e., over the western Pacific in the boreal winter), cirrus clouds are common in the TTL; Shibata et al., 2007; Fujiwara et al., 2009; Massie et al., 2010; Yang et al., 2010; Inai et al., 2012; Shibata et al., 2012). If we could observe ice particles and measure their concentration and size distribution, we could estimate their growth rate under the assumption that a critical relative humidity leads to the initiation of ice nucleation, using the same technique as that employed to estimate the efficiency of dehydration (Sect. 5.3). The history of relative humidity of the air mass could be estimated by using the match method to- gether with the meteorological history of the match air mass. Estimations of growth rate, as well as measurements of the size distribution of ice particles, would enable estimates of the time evolution of the falling speed of ice particles with respect to the surrounding atmosphere. In addition, if we confirm or assume that no ice particles fall from the upper layer, we can estimate the net removal rate of water vapor from the match air parcel. Estimations of these parameters would provide a quantitative description of the efficiency of cold trap dehydration.

\section{Conclusions}

This study investigated evidence for, and the efficiency of, dehydration associated with horizontal advection stratosphere. The water vapor match in the TTL was developed by trajectory calculations with intensive screening procedures to reduce the uncertainty in the results.

The matches were identified by using screening procedures. Some of the matches indicated a decrease in the amount of water vapor between the first and second observations of the water vapor mixing ratio. This finding represents the first direct evidence of dehydration associated with horizontal advection in the TTL.

The matches were investigated in detail in case studies and by statistical analyses. A case study of the $370.0 \mathrm{~K}$ potential temperature revealed a match air parcel that was not effectively dehydrated even though it was supersaturated. On the levels between 350 and $360 \mathrm{~K}$, there were cases that indicate dehydration. Some cases showed a water vapor increase for which there is no reasonable explanation. The statistical features of dehydration for air parcels advected in the TTL were derived from the matches. The results showed that the estimated upper limit of relative humidity with respect to ice, before the initiation of ice nucleation, is approximately $146 \%$. It is suggested that sub-grid-scale temperature fluctuations (or possibly nitric acid trihydrate or other particles) influence dehydration associated with horizontal advection in the lower TTL. The efficiency of dehydration was defined as the relaxation time taken for a supersaturated air parcel to approach the saturation state by the nucleation and removal of ice particles. It is suggested that the dehydration process associated with horizontal advection is efficiently driven in 

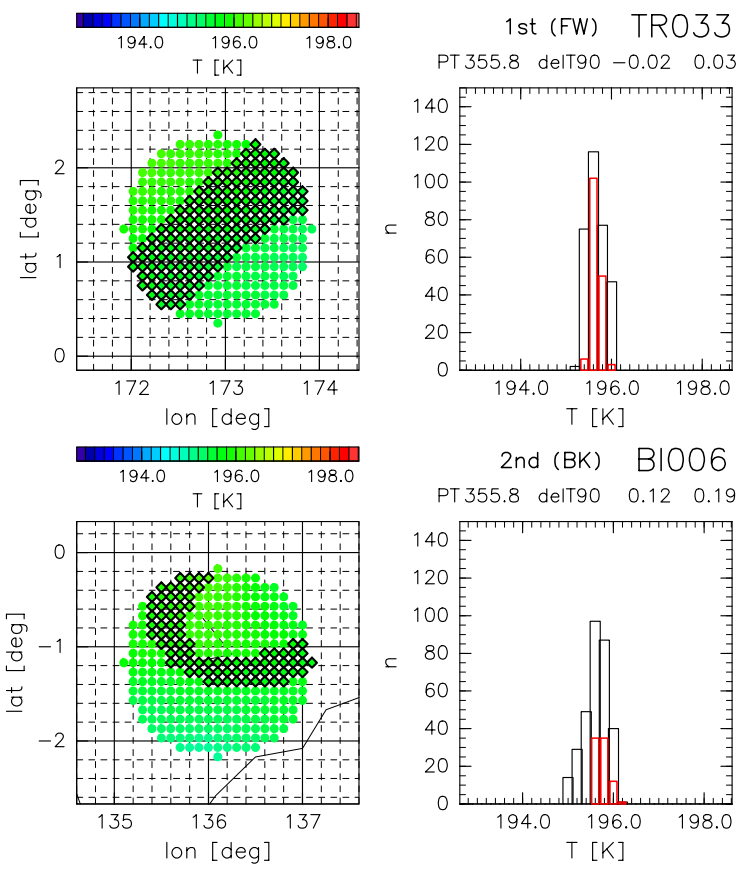

Fig. A1. Representativeness of the match air parcel at Tarawa (top: 05:09 UT, 31 December 2005) and Biak (bottom: 01:49 UT, 6 January 2006). These preliminary matched observations are connected by trajectories at the $355.8 \mathrm{~K}$ potential temperature surface. Left: Match air segments (diamonds) superposed on color-coded temperature of the circular area defined by a match radius. Right: Temperature frequency distribution of the whole segments within the circular area defined by a match radius (black bars) and that for match air segments (red bars).

the lower part of the TTL. These findings may improve our understanding of cloud-microphysical processes in the TTL.

The matches that indicate dehydration were not found at altitudes close to the cold point tropopause (i.e., potential temperature ranging from 370 to $380 \mathrm{~K}$ ). Given that the dehydration around this level determines the amount of water vapor entering the stratosphere, and to improve on the statistical results from this study, additional observation data and more match events at this level are required.

\section{Appendix A}

\section{Detailed descriptions of screening procedures}

\section{A1 Representativeness of the match air parcel}

The match air parcels must be representative of a certain area; otherwise, the values observed by the sonde are not considered as those of the match air parcel. Figure A1 shows the horizontal distribution (left) and frequency distribution (right) of temperature in the match circular areas corresponding to the sonde observations at Tarawa (top) and Biak (bot-
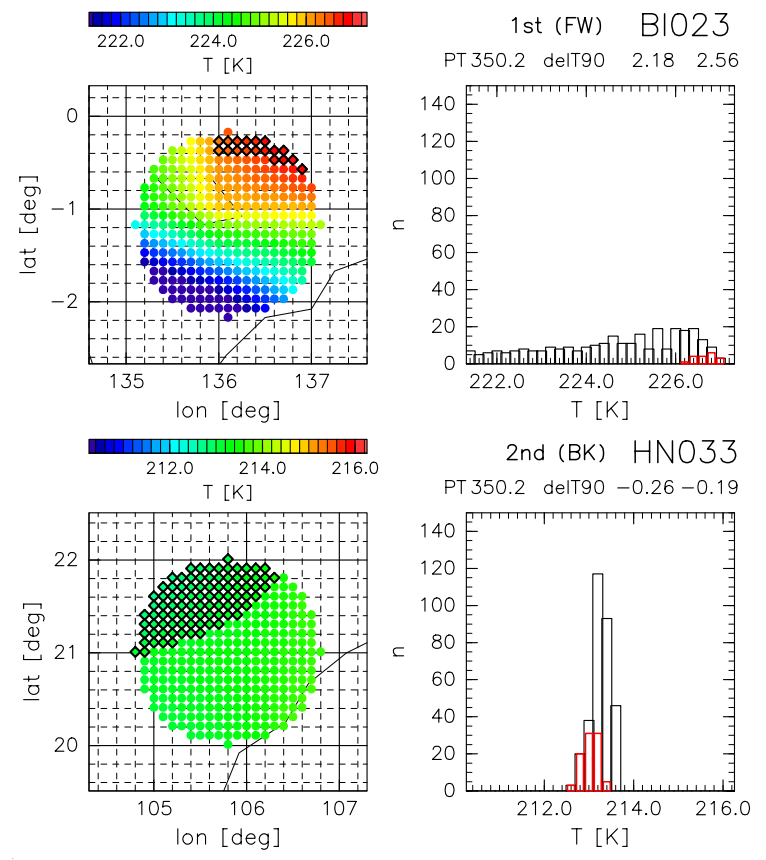

Fig. A2. As for Fig. A1 but for the preliminary match at Biak (top: 22:50 UT, 18 January 2006) and Hanoi (bottom: 06:57 UT, 21 January 2006 ) on the $350.2 \mathrm{~K}$ potential temperature surface.

tom) on the $355.8 \mathrm{~K}$ potential temperature surface. These match air segments are the origins of the forward (backward) trajectories in the upper (lower) panel. In this case, the temperature fields in the circular regions with a match radius for the first and second observations are almost uniform. In addition, the match air segments are widely distributed, covering the match circular areas. Therefore, these match air segments are representative of the temperatures inside both match circles. The confidence intervals of the mean temperature difference between the match air segments and the whole segments inside the match circle are from -0.02 to $0.03 \mathrm{~K}$ for the first observation (Fig. A1 (top)) and from 0.12 to $0.19 \mathrm{~K}$ for the second observation (Fig. A1 (bottom)) at a significance level of 0.1. The intervals were calculated using Welch's test statistic (see Appendix B).

Another example of temperature distributions, shown in Fig. A2, is the same as in Fig. A1 but for a preliminary match between Biak and Hanoi paired by trajectory calculations. In this case, the temperature field in the match circle shows a strong meridional gradient over Biak (top panels in Fig. A2). The match air segments are distributed only at the northern edge of the match circle. Consequently, the subset of match air segments is found only at the right-hand end of the histogram (red bars). As a result, the confidence interval of the mean temperature difference between the match air segments and the whole segments inside the match circle is from 2.18 to $2.56 \mathrm{~K}$ for the first observation (significance level of 0.1 ). Such cases should not be considered in the match analysis. 


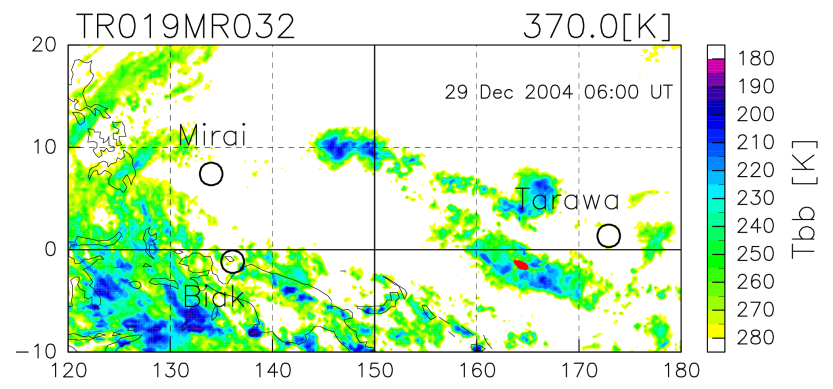

Fig. A3. Match air segments (red area at $\sim 2^{\circ} \mathrm{S}, \sim 164^{\circ} \mathrm{E}$ ) similar to the red dots in Fig. 1 superposed on the distribution of $T_{\mathrm{bb}}$ (color) at 06:00 UT on 29 December 2004. The black circles show the circles of the match radius $\left(1^{\circ}\right)$ centered at individual observational stations.

According to the screening procedure adopted in this study, observational pairs are rejected if the confidence interval of the mean temperature difference between the match air segments and the whole segments inside the match circle does not fall within $[-2.0,2.0] \mathrm{K}$ for the first and second observations at a significance level of 0.1 . This temperature range is determined empirically; the temperature difference of $2.0 \mathrm{~K}$ corresponds to a difference in the saturation water vapor mixing ratio in the TTL of $\sim 0.5$ to $\sim 2.0 \mathrm{ppmv}$.

\section{A2 Convective penetration}

To diagnose convective penetration into the match air parcel, the temperatures of the match air segments $(T)$ and the equivalent blackbody temperature of the underlying cloud $\left(T_{\mathrm{bb}}\right)$ are compared, and the value of $T_{\mathrm{bb}}$ minus $T$ ( $\equiv \delta T_{\mathrm{bb}}$ ) is defined. The values of $T_{\mathrm{bb}}$ are estimated from hourly MTSAT1R/GOES-9 infrared images (Channel 1: 10.3-11.3 $\mu \mathrm{m}$ ). Figure A3 shows an example of advected match air segments similar to the red dots in Fig. 1, superposed on the $T_{\mathrm{bb}}$ distribution at 06:00 UT on 29 December 2004.

To determine an appropriate margin for $\delta T_{\mathrm{bb}}$ in diagnosing the penetration of deep convection, the values of $\left\langle\delta T_{\mathrm{bb}}>\right.$ are calculated as the average for the smallest 10th percentile of $\delta T_{\mathrm{bb}}$ values of the air segments constituting the match air parcel for each time step. Then, the values of $<\delta T_{\mathrm{bb}}>_{\min }$ for each match air parcel are defined as the minimum value of $<\delta T_{\mathrm{bb}}>$ during the advection. Finally, the correlation coefficients of the ozone mixing ratio between the first and second paired observations are calculated as a function of $<\delta T_{\mathrm{bb}}>_{\min }$. The bins are established with a range of $\pm 2.5 \mathrm{~K}$ and an increment of $1.0 \mathrm{~K}$. The left panel of Fig. A4 shows a scatter plot of the first versus the second observed ozone mixing ratios color-coded by each value of $<\delta T_{\mathrm{bb}}>_{\min }$. Light purple symbols indicate preliminary matches above $370 \mathrm{~K}$ that are not used in this procedure, as described below. The correlation coefficients decrease with decreasing values of $<\delta T_{\mathrm{bb}}>_{\min }$. The correlation coefficients are high when the values of $<\delta T_{\mathrm{bb}}>_{\min }$ are higher than $+12 \mathrm{~K}$. There-
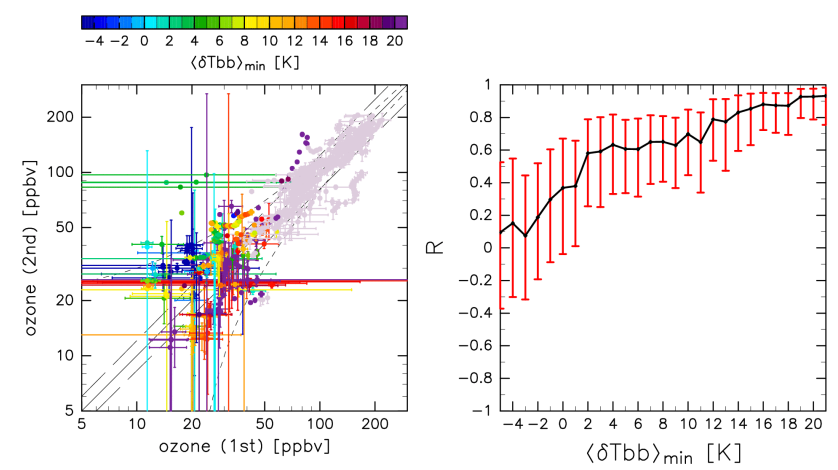

Fig. A4. Examination of convective penetration for the match pairs. Left: Scatter plot of the first versus the second ozone mixing ratios for preliminary matches that passed the screening for "representativeness of match air parcel" color-coded by the value of $<\delta T_{\mathrm{bb}}>_{\text {min }}$ (see text for details). Right: Dependency of correlation coefficients for ozone mixing ratios between the first and second observations on the value of $\left\langle\delta T_{\mathrm{bb}}\right\rangle_{\min }$. The error bars are $99 \%$ confidence intervals.

fore, we adopt $+12 \mathrm{~K}$ as the critical value of the margin for $<\delta T_{\mathrm{bb}}>_{\min }$.

This method cannot be applied to air segments advected above the temperature inversion at the cold point, as the distance between the air parcel and underlying cloud cannot be estimated from the comparison of $T$ and $T_{\mathrm{bb}}$ at those levels. Although some deep convection penetrates the stratosphere up to the $420 \mathrm{~K}$ isentropic level (Khaykin et al., 2009; Iwasaki et al., 2010) on rare occasions, we do not apply the screening procedure to air parcels above the $370 \mathrm{~K}$ potential temperature level. Instead, the matches above the $370 \mathrm{~K}$ level that pass all the screening steps are carefully checked with reference to individual sonde profiles (see Sect. 4.1).

An alternative method to diagnose convective penetration, such as that used by Suzuki et al. (2010) employing cloud top height data by Hamada and Nishi (2010), is not used in the present analysis because the data set does not fully cover the SOWER campaign period and region.

\section{A3 Validity of the isentropic treatment}

We establish an upper limit of the advection time for which the isentropic treatment is valid by using ozone conservation, because our trajectory calculations are made under the assumption of adiabatic conditions. Figure A5 is the same as Fig. A4 but for assessing an acceptable advection time. The colors in the left panel indicate the advection time between the first and second observations for each preliminary match. The symbols in light purple represent preliminary matches above the $380 \mathrm{~K}$ isentrope, which are not used in this procedure because the horizontal scale of the ozone variations becomes so large at this altitude that the correlation coefficients between the observed ozone mixing ratios show uniformly large values regardless of the match/non-match conditions. 

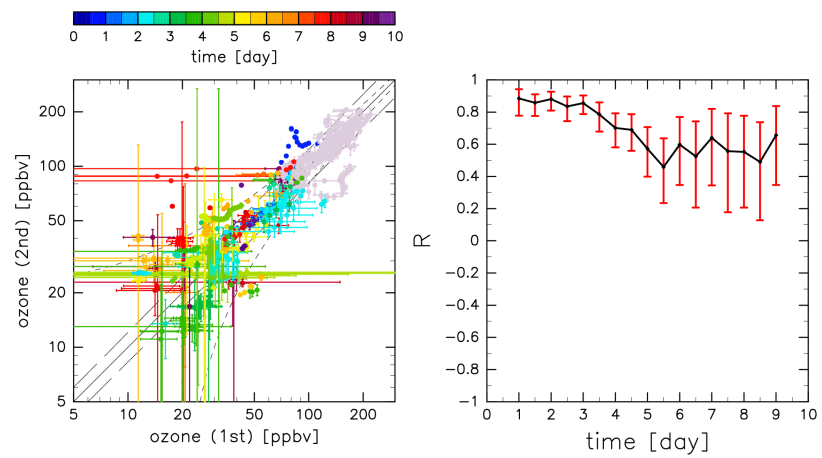

Fig. A5. As for Fig. A4 but for an examination of the acceptable advection time for the isentropic treatment.

The right panel of Fig. A5 shows the dependency of the correlation coefficients of ozone mixing ratios between the first and second observations on advection time. The correlation coefficients are calculated using the data in the left panel using bins of \pm 1.0 day with an increment of 0.5 days depending on the advection time of each match air parcel. The correlation coefficients decrease as the advection time increases, due to the cumulative effect of errors in the isentropic trajectory calculations. In this study, we choose 5 days as the threshold of advection time, since the minimum value of the correlation coefficients is found at 5.5 days.

\section{A4 Consistency between sonde data and the analysis field}

The criterion employed in the screening procedure for consistency between the sonde data and the analysis field is assessed by considering the difference in temperature between the ECMWF analysis and sonde data: $T_{\mathrm{ECMWF}}$ minus $T(\equiv \delta T)$ at the same potential temperature surface. Here, $T_{\mathrm{ECMWF}}$ is the temperature of the ECMWF analysis field interpolated to the location of the sonde station at $50 \mathrm{~min}$ after the launch. This assessment is also performed by using a similar method to those outlined in Appendices A2 and A3; i.e., employing the correlation coefficients between the first and second ozone mixing ratios. In this examination, the correlation coefficients are calculated as a function of $\delta T$ with bins of $\pm 1.0 \mathrm{~K}$ and an increment of $0.5 \mathrm{~K}$. This procedure is conducted for both the first and second observations for each preliminary match. Figure A6 is the same as Fig. A5 but examines the consistency between sonde data and the analysis field. The data in the left panel are color-coded by values of $\delta T$. The preliminary matches above the $380 \mathrm{~K}$ isentrope are not used in this procedure, for the same reason as that explained in Appendix A3. The right panel shows the dependency of the correlation coefficients on $\delta T$. There is a broad maximum around zero, although some asymmetry is apparent. There are remarkable decreases in the correlation coefficient at -5.0 and $+6.0 \mathrm{~K}$, and we cannot explain the re-
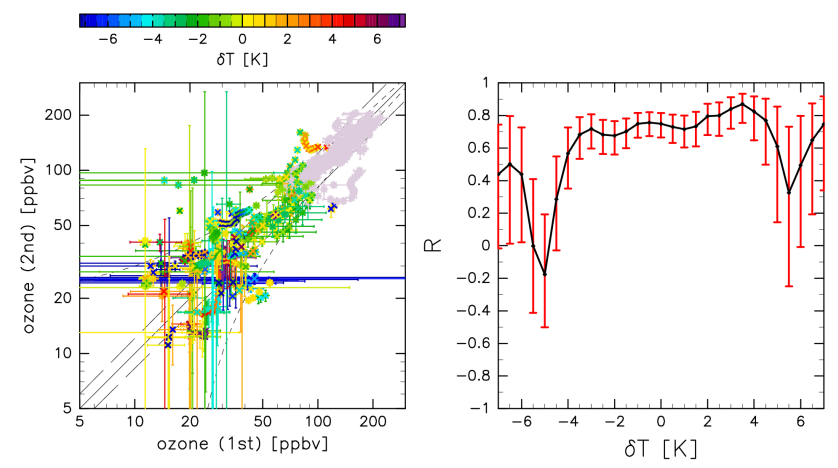

Fig. A6. As for Fig. A5 but for examining the consistency between sonde data and the analysis field.

covery in values outside of these limits. To assure a relatively high correlation between the paired ozone concentrations, we adopt a range of temperature differences between -4.0 and $5.0 \mathrm{~K}$ as the criterion for assessing the consistency between sonde data and the analysis field.

\section{Appendix B}

\section{Welch's test statistic}

Welch's $t$-test defines the statistic $T$ as follows:

$$
T=\frac{\overline{x_{1}}-\overline{x_{2}}}{\sqrt{\frac{s_{1}^{2}}{N_{1}}+\frac{s_{2}^{2}}{N_{2}}}},
$$

where $\left(\overline{x_{1}}, \overline{x_{2}}\right),\left(s_{1}, s_{2}\right)$, and $\left(N_{1}, N_{2}\right)$ indicate the mean values, the standard deviations, and the numbers of first and second samples, respectively. This $T$ value follows the $t$ distribution corresponding to the degree of freedom $m$ calculated from

$$
m=\frac{\left(\frac{s_{1}{ }^{2}}{N_{1}}+\frac{s_{2}{ }^{2}}{N_{2}}\right)^{2}}{\frac{s_{1}{ }^{2}}{N_{1}{ }^{2}\left(N_{1}-1\right)}+\frac{s_{2}{ }^{4}}{N_{2}{ }^{2}\left(N_{2}-1\right)}} .
$$

Referring to this value, the confidence interval of the difference between the two population means $\left(\mu_{1}-\mu_{2}\right)$ is estimated from the following:

$$
\begin{aligned}
& \left(\overline{x_{1}}-\overline{x_{2}}\right)-t_{m}\left(\frac{\alpha}{2}\right) \sqrt{\frac{s_{1}^{2}}{N_{1}}+\frac{s_{2}^{2}}{N_{2}}} \leq \mu_{1}-\mu_{2} \leq\left(\overline{x_{1}}-\overline{x_{2}}\right) \\
& +t_{m}\left(\frac{\alpha}{2}\right) \sqrt{\frac{s_{1}^{2}}{N_{1}}+\frac{s_{2}^{2}}{N_{2}}},
\end{aligned}
$$

with a confidence level of $100(1-2 \alpha) \%$. In this study, this equation is applied to the temperature of the match air segments (subscript 1) and to the temperature of the whole segments within the circle of match radius $\left(1^{\circ}\right)$ (subscript 2 ). 
Appendix C

\section{List of all matches}

Table C1. List of all 107 matches. TR, MR, BD, HN, KT, and BI represent the sondes launched from Tarawa, R/V Mirai, Bandung, Ha Noi, Kototabang, and Biak, respectively.

\begin{tabular}{|c|c|c|}
\hline First & Second & Altitude $[\mathrm{K}]$ \\
\hline TR015 & MR023 & 354.2 \\
\hline TR015 & MR023 & 354.8 \\
\hline TR015 & MR023 & 355.0 \\
\hline TR015 & MR023 & 355.2 \\
\hline TR015 & MR023 & 355.4 \\
\hline TR015 & MR023 & 355.6 \\
\hline TR015 & MR023 & 355.8 \\
\hline TR015 & MR023 & 356.0 \\
\hline TR015 & MR023 & 356.4 \\
\hline TR015 & MR023 & 356.6 \\
\hline TR015 & MR023 & 356.8 \\
\hline BD218 & BD219 & 361.0 \\
\hline BD218 & BD219 & 377.0 \\
\hline TR029 & TR030 & 352.4 \\
\hline TR029 & TR030 & 352.6 \\
\hline TR029 & TR030 & 352.8 \\
\hline TR029 & TR030 & 353.0 \\
\hline TR029 & TR030 & 353.2 \\
\hline TR029 & TR030 & 353.4 \\
\hline TR029 & TR030 & 353.6 \\
\hline TR029 & TR030 & 353.8 \\
\hline TR029 & TR030 & 354.0 \\
\hline TR029 & TR030 & 356.4 \\
\hline TR029 & TR030 & 356.6 \\
\hline TR029 & TR030 & 356.8 \\
\hline TR029 & TR030 & 357.0 \\
\hline TR029 & TR030 & 357.2 \\
\hline TR029 & TR030 & 357.4 \\
\hline TR029 & TR030 & 357.6 \\
\hline BI028 & HN062 & 355.4 \\
\hline HN061 & TR052 & 361.0 \\
\hline KT023 & KT025 & 369.0 \\
\hline KT023 & KT025 & 370.0 \\
\hline KT023 & KT025 & 371.0 \\
\hline KT023 & KT025 & 372.0 \\
\hline KT023 & KT025 & 373.0 \\
\hline KT023 & KT025 & 374.0 \\
\hline BI030 & BI031 & 377.0 \\
\hline BI030 & BI031 & 378.0 \\
\hline BI030 & BI032 & 378.0 \\
\hline BI030 & BI032 & 379.0 \\
\hline BI029 & BI030 & 379.0 \\
\hline BI029 & BI030 & 380.0 \\
\hline BI029 & BI030 & 381.0 \\
\hline BI029 & BI031 & 379.0 \\
\hline BI031 & BI032 & 379.0 \\
\hline BI031 & BI032 & 380.0 \\
\hline BI031 & BI032 & 381.0 \\
\hline BI031 & BI032 & 382.0 \\
\hline BI031 & BI032 & 383.0 \\
\hline BI028 & BI030 & 384.0 \\
\hline BI028 & BI030 & 385.0 \\
\hline BI028 & BI030 & 386.0 \\
\hline
\end{tabular}

Table C1. Continued.

\begin{tabular}{|c|c|c|}
\hline first & second & altitude $[\mathrm{K}]$ \\
\hline TR051 & TR054 & 385.0 \\
\hline TR051 & TR054 & 386.0 \\
\hline TR051 & TR054 & 387.0 \\
\hline TR051 & TR054 & 388.0 \\
\hline TR051 & TR054 & 389.0 \\
\hline TR051 & TR054 & 390.0 \\
\hline TR051 & TR054 & 391.0 \\
\hline KT022 & KT023 & 387.0 \\
\hline KT022 & КT023 & 388.0 \\
\hline KT022 & KT023 & 389.0 \\
\hline KT022 & KT023 & 390.0 \\
\hline KT022 & KT023 & 391.0 \\
\hline KT022 & КT023 & 392.0 \\
\hline КT022 & КT023 & 393.0 \\
\hline КT022 & КT023 & 394.0 \\
\hline КT022 & КT023 & 395.0 \\
\hline KT022 & КT023 & 396.0 \\
\hline KT022 & КT023 & 397.0 \\
\hline KT022 & КT023 & 398.0 \\
\hline KT022 & КT023 & 399.0 \\
\hline KT022 & КT023 & 400.0 \\
\hline BI027 & BI028 & 391.0 \\
\hline BI027 & BI028 & 392.0 \\
\hline BI027 & BI028 & 393.0 \\
\hline BI027 & BI028 & 394.0 \\
\hline BI027 & BI028 & 395.0 \\
\hline TR053 & TR054 & 392.0 \\
\hline TR053 & TR054 & 393.0 \\
\hline TR053 & TR054 & 394.0 \\
\hline КT024 & KT025 & 400.0 \\
\hline BI039 & HN093 & 350.4 \\
\hline BI039 & HN093 & 352.4 \\
\hline KT031 & KT032 & 391.0 \\
\hline KT031 & KT032 & 392.0 \\
\hline KT031 & KT032 & 393.0 \\
\hline KT031 & KT032 & 394.0 \\
\hline BI037 & KT034 & 364.0 \\
\hline BI036 & KT034 & 387.0 \\
\hline BI036 & KT034 & 388.0 \\
\hline BI036 & КT034 & 389.0 \\
\hline BI036 & KT034 & 390.0 \\
\hline BI036 & KT034 & 391.0 \\
\hline BI038 & BI039 & 396.0 \\
\hline BI037 & BI038 & 395.0 \\
\hline BI037 & BI038 & 396.0 \\
\hline BI037 & BI038 & 397.0 \\
\hline BI037 & BI038 & 398.0 \\
\hline BI037 & BI038 & 399.0 \\
\hline BI037 & BI038 & 400.0 \\
\hline BI037 & BI039 & 396.0 \\
\hline BI037 & BI039 & 397.0 \\
\hline BI037 & BI039 & 398.0 \\
\hline BI037 & BI039 & 399.0 \\
\hline HN112 & HN113 & 374.0 \\
\hline
\end{tabular}


Acknowledgements. The authors are grateful to the members of Lembaga Penerbangan dan Antariksa Nasional (LAPAN) of Indonesia, the Meteorological Office of Tarawa, Kiribati, and the Aero-Meteorological Observatory of Hanoi, Vietnam. We also thank the Japan Agency for Marine-Earth Science and Technology (JAMSTEC) and Global Ocean Development, Inc. (GODI) for their support on board the R/V Mirai. This work was supported by KAKENHI, Japan Society for the Promotion of Science, Japan (15204043, 16740264, 18204041, 21244072, and 22241004) and by the Global Environment Research Fund of the Ministry of the Environment, Japan (A-1 and A-071). GOES-9 and MTSAT-1R data were obtained from Kochi University, Japan. The figures were produced by the GFD-DENNOU Library. Comments by S. Fueglistaler and two anonymous reviewers helped to improve the manuscript.

Edited by: G. Stiller

\section{References}

Brasseur, G. and Solomon, S.: Aeronomy of the Middle Atmosphere: Chemistry and Physics of the Stratosphere and Mesosphere, Dordrecht, Boston, 1986.

Chepfer, H. and Noel, V.: A tropical "NAT-like" belt observed from space, Geophys. Res. Lett., 36, L03813, doi:10.1029/2008GL036289, 2009.

Corti, T., Luo, B. P., Fu, Q., Vömel, H., and Peter, T.: The impact of cirrus clouds on tropical troposphere-to-stratosphere transport, Atmos. Chem. Phys., 6, 2539-2547, doi:10.5194/acp-6-25392006, 2006.

Crutzen, P. J. and Arnold, F.: Nitric acid cloud formation in the cold Antarctic stratosphere: a major cause for the springtime "ozone hole", Nature, 342, 651-655, 1986.

Dessler, A. E.: The effect of deep, tropical convection on the tropical tropopause layer, J. Geophys. Res., 107, 4033, doi:10.1029/2001JD000511, 2002.

Folkins, I., Braun, C., Thompson, A., and Witte, J.: Tropical ozone as an indicator of deep convection, J. Geophys. Res., 107, 4184, doi:10.1029/2001JD001178, 2002.

Forster, P. M. d. F. and Shine, K. P.: Stratospheric water vapour changes as a possible contributor to observed stratospheric cooling, Geophys. Res. Lett., 26, 3309-3312, 1999.

Fueglistaler, S., Wernli, H., and Peter, T.: Tropical troposphereto-stratosphere transport inferred from trajectory calculations, J. Geophys. Res., 109, D03108, doi:10.1029/2003JD004069, 2004.

Fueglistaler, S., Bonazzola, M., Haynes, P. H., and Peter, T.: Stratospheric water vapor predicted from the Lagrangian temperature history of air entering the stratosphere in the tropics, J. Geophys. Res., 110, D08107, doi:10.1029/2004JD005516, 2005.

Fueglistaler, S., Dessler, A. E., Dunkerton, T. J., Folkins, I., Fu, Q., and Mote, P. W.: TROPICAL TROPOPAUSE LAYER, Rev. Geophys., 47, RG1004, doi:10.1029/2008RG000267, 2009.

Fujiwara, M., Shiotani, M., Hasebe, F., Vömel, H., Oltmans, S. J., Ruppert, P. W., Horinouchi, T., and Tsuda, T.: Performance of the Meteolabor "Snow White" chilled-mirror hygrometer in the tropical troposphere: Comparisons with the Vaisala RS80 A/HHumicap sensors, J. Atmos. Ocean. Technol., 20, 1534-1542, 2003.
Fujiwara, M., Iwasaki, S., Shimizu, A., Inai, Y., Shiotani, M., Hasebe, F., Matsui, I., Sugimoto, N., Okamoto, H., Nishi, N., Hamada, A., Sakazaki, T., and Yoneyama, K.: Cirrus Observations in the Tropical Tropopause Layer Over the Western Pacific, J. Geophys. Res., 114, D09304, doi:10.1029/2008JD011040, 2009.

Fujiwara, M., Vömel, H., Hasebe, F., Shiotani, M., Ogino, S.Y., Iwasaki, S., Nishi, N., Shibata, T., Shimizu, K., Nishimoto, E., Canossa, J. M. V., Selkirk, H. B., and Oltmans, S. J.: Seasonal to decadal variations of water vapor in the tropical lower stratosphere observed with balloon-borne cryogenic frost point hygrometers, J. Geophys. Res., 115, D18304, doi:10.1029/2010JD014179, 2010.

Gill, A. E.: Some simple solutions for heat-induced tropical circulation, Q. J. R. Meteorol. Soc., 106, 447-462, 1980.

Goff, A. J. and Gratch, S.: Low-pressure properties of water from -160 to $212^{\circ}$ F, Trans. Amer. Soc. Heat. Vent. Eng., 52, 95-122, 1946.

Hamada, A. and Nishi, N.: Development of a Cloud-Top Height Estimation Method by Geostationary Satellite Split-Window Measurements Trained with CloudSat Data, J. Appl. Meteor. Climatol., 49, 2035-2049, doi:10.1175/2010JAMC2287.1, 2010.

Hasebe, F., Fujiwara, M., Nishi, N., Shiotani, M., Vömel, H., Oltmans, S., Takashima, H., Saraspriya, S., Komala, N., and Inai, Y.: In situ observations of dehydrated air parcels advected horizontally in the Tropical Tropopause Layer of the western Pacific, Atmos. Chem. Phys., 7, 803-813, doi:10.5194/acp-7-803-2007, 2007.

Hasebe, F., Inai, Y., Shiotani, M., Fujiwara, M., Vömel, H., Nishi, N., Ogino, S.-Y., Shibata, T., Iwasaki, S., N.Komala, Peter, T., and Oltmans, S. J.: Cold trap dehydration in the tropical tropopause layer characterized by SOWER chilled-mirror hygrometer network data in the Tropical Pacific, Atmos. Chem. Phys., 13, 4393-4411, doi:10.5194/acp-13-4393-2013, 2013.

Hatsushika, H. and Yamazaki, K.: Stratospheric drain over Indonesia and dehydration within the tropical tropopause layer diagnosed by air parcel trajectories, J. Geophys. Res., 108, 4610, doi:10.1029/2002JD002986, 2003.

Highwood, E. J. and Hoskins, B. J.: The tropical tropopause, Q. J. Roy. Meteorol. Soc., 124, 1579-1604, 1998.

Holton, J. R. and Gettelman, A.: Horizontal transport and the dehydration of the stratosphere, Geophys. Res. Lett., 28, 2799-2802, 2001.

Hurst, D. F., Oltmans, S. J., Vömel, H., Rosenlof, K. H., Davis, S. M., Ray, E. A., Hall, E. G., and Jordan, A. F.: Stratospheric water vapor trends over Boulder, Colorado: Analysis of the 30 year Boulder record, J. Geophys. Res., 116, D02306, doi:10.1029/2010JD015065, 2011.

Inai, Y., Hasebe, F., Shimizu, K., and Fujiwara, M.: Correction of Radiosonde Pressure and Temperature Measurements Using Simultaneous GPS Height Data, SOLA, 5, 109-112, doi:10.2151/sola.2009-028, 2009.

Inai, Y., Shibata, T., Fujiwara, M., Hasebe, F., and Vömel, H.: High supersaturation inside cirrus in well-developed tropical tropopause layer over Indonesia, Geophys. Res. Lett., 39, L20811, doi:10.1029/2012GL053638, 2012.

Iwasaki, S., Maruyama, K., Hayashi, M., Ogino, S.-Y., Ishimoto, H., Tachibana, Y., Shimizu, A., Matsui, I., Sugimoto, N., Yamashita, K., Saga, K., Iwamoto, K., Kamiakito, Y., Chabang- 
born, A., Thana, B., Hashizume, M., Koike, T., and Oki, T.: Characteristics of aerosol and cloud particle size distributions in the tropical tropopause layer measured with optical particle counter and lidar, Atmos. Chem. Phys., 7, 3507-3518, doi:10.5194/acp7-3507-2007, 2007.

Iwasaki, S., Shibata, T., Nakamoto, J., Okamoto, H., Ishimoto, H., and Kubota, H.: Characteristics of deep convection measured by using the A-train constellation, J. Geophys. Res., 115, D06207, doi:10.1029/2009JD013000, 2010.

Jensen, E. J. and Pfister, L.: Transport and freeze-drying in the tropical tropopause layer, J. Geophys. Res., 109, D02207, doi:10.1029/2003JD004022, 2004.

Kärcher, B. and Lohmann, U.: A parameterization of cirrus cloud formation: Heterogeneous freezing, J. Geophys. Res., 108, 4402, doi:10.1029/2002JD003220, 2003.

Khaykin, S., Pommereau, J. P., Korshunov, L., Yushkov, V., Nielsen, J., Larsen, N., Christensen, T., Garnier, A., Lukyanov, A., and Williams, E.: Hydration of the Lower Stratosphere by ice Crystal Geysers Over Land Convective Systems, Atmos. Chem. Phys., 9, 2275-2287, 2009,

http://www.atmos-chem-phys.net/9/2275/2009/.

Kley, D., Russell III, J. M., and Phillips, C.: SPARC Assessment of Upper Tropospheric and Stratospheric Water Vapour, WCRP 113 WMO/TD-No. 1043 SPARC Report No. 2, 2000.

Koop, T., Luo, B., Tsias, A., and Peter, T.: Water Activity as the Determinant for Homogeneous ice Nucleation in Aqueous Solutions, Nature, 406, 611-614, 2000.

Krämer, M., Schiller, C., Afchine, A., Bauer, R., Gensch, I., Mangold, A., Schlicht, S., Spelten, N., Sitnikov, N., Borrmann, S., de Reus, M., and Spichtinger, P.: Ice supersaturations and cirrus cloud crystal numbers, Atmos. Chem. Phys., 9, 3505-3522, doi:10.5194/acp-9-3505-2009, 2009.

List, R. J.: Smithsonian Meteorological Tables, 5th edition, Smithsonian Institution, Washington, DC, USA, 1984.

Massie, S. T., Gille, J., Craig, C., Khosravi, R., Barnett, J., Read, W., and Winker, D.: HIRDLS and CALIPSO observations of tropical cirrus, J. Geophys. Res., 115, D00H11, doi:10.1029/2009JD012100, 2010.

Matsuno, T.: Quasi-geostrophic motions in the equatorial area, J. Meteorol. Soc. Jpn., 44, 25-43, 1966.

Möhler, O., Stetzer, O., Schaefers, S., Linke, C., Schnaiter, M., Tiede, R., Saathoff, H., Krämer, M., Mangold, A., Budz, P., Zink, P., Schreiner, J., Mauersberger, K., Haag, W., Kärcher, B., and Schurath, U.: Experimental investigation of homogeneous freezing of sulphuric acid particles in the aerosol chamber AIDA, Atmos. Chem. Phys., 3, 211-223, doi:10.5194/acp-3-211-2003, 2003.

Murray, B. J., Wilson, T. W., Dobbie, S., Cui, Z., Al-Jumur, S. M. R. K., Möhler, O., Schnaiter, M., Wagner, R., Benz, S., Niemand, M., Saathoff, H., Ebert, V., Wagner, S., and Kärcher, B.: Heterogeneous nucleation of ice particles on glassy aerosols under cirrus conditions, Nature Geosci., 3, 233-237, doi:10.1038/NGEO817, 2010.

Oltmans, S. J. and Hofmann, D. J.: Increase in lower-stratospheric water vapour at a mid-latitude Northern Hemisphere site from 1981 to 1994, Nature, 374, 146-149, 1995.

Oltmans, S. J., Vömel, H., Hofmann, D. J., Rosenlof, K. H., and Kley, D.: The increase in stratospheric water vapor from balloonborne, frostpoint hygrometer measurements at 20 Washing- ton, D.C., and Boulder, Colorado, Geophys. Res. Lett., 27, 34533456, doi:10.1029/2000GL012133, 2000.

Ploeger, F., Fueglistaler, S., Grooß, J.-U., Günther, G., Konopka, P., Liu, Y., Müller, R., Ravegnani, F., Schiller, C., Ulanovski, A., and Riese, M.: Insight from ozone and water vapour on transport in the tropical tropopause layer (TTL), Atmos. Chem. Phys., 11, 407-419, doi:10.5194/acp-11-407-2011, 2011.

Pruppacher, H. R. and Klett, J. D.: Microphysics of Clouds and Precipitation, second edition, Kluwer Academic Publishers, 1997.

Read, W. G., Wu, D. L., Waters, J. W., and Pumphrey, H. C.: Dehydration in the tropical tropopause layer: Implications from the UARS microwave limb sounder, J. Geophys. Res., 109, D06110, doi:10.1029/2003JD004056, 2004.

Rex, M., Harris, N. R. P., von der Gathen, P., Lehmann, R., Braathen, G. O., Reimer, E., Beck, A., Chipperfield, M., Alfier, R., Allaart, M., O’Connor, F., Dier, H., Dorokhov, V., Fast, H., Gil, M., Kyro, E., Litynska, Z., Mikkelsen, I. S., Molyneux, M., Nakane, H., Rummukainen, M., Viatte, P., and Wenger, J.: Prolonged stratospheric ozone loss in the 1995.96 Arctic winter, Nature, 389, 835-838, 1997.

Rex, M., von der Gathen, P., Harris, N. R. P., Lucic, D., Knudsen, B. M., Braathen, G. O., Reid, S. J., Backer, H. D., Claude, H., Fabian, R., Fast, H., Gil, M., Kyrö, E., Mikkelsen, I. S., Rummukainen, M., Smit, H. G., Stähelin, J., Varotsos, C., and Zaitcev, I.: In situ measurements of stratospheric ozone depletion rates in the Arctic winter 1991/1992: A Lagrangian approach, J. Geophys. Res., 103, 5843-5854, 1998.

Saitoh, N., Hayashida, S., Sugita, T., Nakajima, H., Yokota, T., and Sasano, Y.: Variation in PSC Occurrence Observed with ILAS-II over the Antarctic in 2003, SOLA, 2, 72-75, doi:10.2151/sola.2006-019, 2006.

Scherer, M., Vömel, H., Fueglistaler, S., Oltmans, S. J., and Staehelin, J.: Trends and variability of midlatitude stratospheric water vapour deduced from the re-evaluated Boulder balloon series and HALOE, Atmos. Chem. Phys., 8, 1391-1402, doi:10.5194/acp8-1391-2008, 2008.

Sherwood, S. C., Chae, J.-H., Minnis, P., and McGill, M.: Underestimation of deep convective cloud tops by thermal imagery, Geophys. Res. Lett., 31, L11102, doi:10.1029/2004GL019699, 2004.

Shibata, T., Vömel, H., Hamdi, S., Kaloka, S., Hasebe, F., Fujiwara, M., and Shiotani, M.: Tropical cirrus clouds near cold point tropopause under ice supersaturated conditions observed by lidar and balloon-borne cryogenic frost point hygrometer, J. Geophys. Res., 112, D03210, doi:10.1029/2006JD007361, 2007.

Shibata, T., Hayashi, M., Naganuma, A., Hara, N., Hara, K., Hasebe, F., Shimizu, K., Komala, N., Inai, Y., Vömel, H., Hamdi, S., Iwasaki, S., Fujiwara, M., Shiotani, M., Ogino, S.-Y., and Nishi, N.: Cirrus cloud appearance in a volcanic aerosol layer around the tropical cold point tropopause over Biak, Indonesia, in January 2011, J. Geophys. Res., 117, D11209, doi:10.1029/2011JD017029., 2012.

Smit, H. G. J., Sträter, W., Johnson, B. J., Oltmans, S. J., Davies, J., Tarasick, D. W., Hoegger, B., Stubi, R., Schmidlin, F. J., Northam, T., Thompson, A. M., Witte, J. C., Boyd, I. S., and Posny, F.: Assessment of the performance of ECC-ozonesondes under quasi flight conditions in the environmental simulation chamber: insights from the Jülich Ozone Sonde Intercomparison Experiment (JOSIE), J. Geophys. Res., 112, D19306, 
doi:10.1029/2006JD007308, 2007.

Solomon, S., Rosenlof, K. H., Portmann, R. W., Daniel, J. S., Davis, S. M., Sanford, T. J., and Plattner, G.-K.: Contributions of Stratospheric Water Vapor to Decadal Changes in the Rate of Global Warming, Science, 327, 1219-1223, 2010.

Steinwagner, J., Fueglistaler, S., Stiller, G., von Clarmann, T., Kiefer, M., Borsboom, P.-P., van Delden, A., and Röckmann, T.: Tropical dehydration processes constrained by the seasonality of stratospheric deuterated water, Nature Geosci., 3, 262-266, doi:10.1038/NGEO822, 2010.

Stenke, A. and Grewe, V.: Simulation of stratospheric water vapor trends: impact on stratospheric ozone chemistry, Atmos. Chem. Phys., 5, 1257-1272, doi:10.5194/acp-5-1257-2005, 2005.

Suzuki, J., Fujiwara, M., Hamada, A., Inai, Y., Yamaguchi, J., Shirooka, R., Hasebe, F., and Takano, T.: Cloud-Top Height Variability Associated with Equatorial Kelvin Waves in the Tropical Tropopause Layer during the Mirai Indian Ocean cruise for the Study of the MJO-Convection Onset (MISMO) Campaign, SOLA, 6, 97-110, doi:10.2151/sola.2010-025, 2010.

Takashima, H., Eguchi, N., and Read, W.: A short duration cooling event around the tropical tropopause and its effect on water vapor, Geophys. Res. Lett., 37, L20804, doi:10.1029/2010GL044505, 2010.

Voigt, C., Schlager, H., Roiger, A., Stenke, A., de Reus, M., Borrmann, S., Jensen, E., Schiller, C., Konopka, P., and Sitnikov, N.: Detection of reactive nitrogen containing particles in the tropopause region - evidence for a tropical nitric acid trihydrate (NAT) belt, Atmos. Chem. Phys., 8, 7421-7430, doi:10.5194/acp-8-7421-2008, 2008.

Vömel, H. and Diaz, K.: Ozone sonde cell current measurements and implications for observations of near-zero ozone concentrations in the tropical upper troposphere, Atmos. Meas. Techn., 3, 495-505, doi:10.5194/amt-3-495-2010, 2010.
Vömel, H., Fujiwara, M., Shiotani, M., Hasebe, F., Oltmans, S. J., and Barnes, J. E.: The behavior of the Snow White chilled-mirror hygrometer in extremely dry conditions, J. Atmos. Ocean. Technol., 20, 1560-1567, 2003.

Vömel, H., David, D., and Smith, K.: Accuracy of Tropospheric and Stratospheric Water Vapor Measurements by the Cryogenic Frost Point Hygrometer: Instrumental details and observations, J. Geophys. Res., 112, D08305, doi:10.1029/2006JD007224, 2007.

von der Gathen, P., Rex, M., Harris, N. R. P., Lucic, D., Knudsen, B. M., Braathen, G. O., Backer, H. D., Fabian, R., Fast, H., Gil, M., Kyrö, E., Mikkelsen, I. S., Rummukainen, M., Stähelin, J., and Varotsos, C.: Observational evidence for chemical ozone depletion over the Arctic in winter 1991-92, Nature, 375, 131-134, 1995.

Wennberg, P. O., Hanisco, T. F., Jaeglé, L., Jacob, D. J., Hintsa, E. J., Lanzendorf, E. J., Anderson, J. G., Gao, R.-S., Keim, E. R., Donnelly, S. G., Negro, L. A. D., Fahey, D. W., McKeen, S. A., Salawitch, R. J., Webster, C. R., May, R. D., Herman, R. L., Proffitt, M. H., Margitan, J. J., Atlas, E. L., Schauffler, S. M., Flocke, F., McElroy, C. T., and Bui, T. P.: Hydrogen Radicals, Nitrogen Radicals, and the Production of $\mathrm{O}_{3}$ in the Upper Troposphere, Science, 279, 49-53, 1998.

Yang, Q., Fu, Q., and Hu, Y.: Radiative impacts of clouds in the tropical tropopause layer, J. Geophys. Res., 115, D00H12, doi:10.1029/2009JD012393, 2010. 